\title{
A bilayer tissue culture model of the bovine alveolus [version
}

\section{1; peer review: 3 approved with reservations]}

\author{
Diane Lee(iD), Mark Chambers (iD) \\ School of Veterinary Medicine, University of Surrey, Guildford, Surrey, GU2 7AL, UK
}

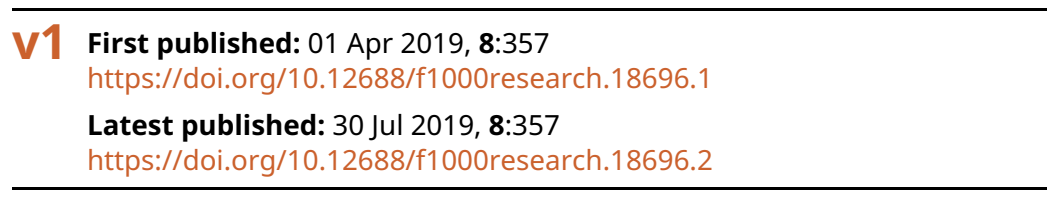

\section{Abstract}

The epithelial lining of the lung is often the first point of interaction between the host and inhaled pathogens, allergens and medications. Epithelial cells are therefore the main focus of studies which aim to shed light on host-pathogen interactions, to dissect the mechanisms of local host immunity and study toxicology. If these studies are not to be conducted exclusively in vivo, it is imperative that in vitro models are developed with a high in vitro-in vivo correlation. We describe here a co-culture bilayer model of the bovine alveolus, designed to overcome some of the limitations encountered with mono-culture and live animal models. Our system includes bovine pulmonary arterial endothelial cells (BPAECs) seeded onto a permeable membrane in 24 well Transwell format. The BPAECs are overlaid with immortalised bovine alveolar type II epithelial cells and the bilayer cultured at airliquid interface for 14 days before use; in our case to study hostmycobacterial interactions.

Characterisation of novel cell lines and the bilayer model have provided compelling evidence that immortalised bovine alveolar type II cells are an authentic substitute for primary alveolar type II cells and their culture as a bilayer in conjunction with BPAECs provides a physiologically relevant in vitro model of the bovine alveolus. The bilayer model may be used to study dynamic intracellular and extracellular host-pathogen interactions, using proteomics, genomics, live cell imaging, in-cell ELISA and confocal microscopy. The model presented in this article enables other researchers to establish an in vitro model of the bovine alveolus that is easy to set up, malleable and serves as a comparable alternative to in vivo models, whilst allowing study of early host-pathogen interactions, currently not feasible in vivo . The model therefore achieves one of the 3Rs objectives in that it replaces the use of animals in research of bovine respiratory diseases.

\section{Keywords}

Replacement, NC3Rs, bovine, alveolus, type II, endothelial, air-liquid interface

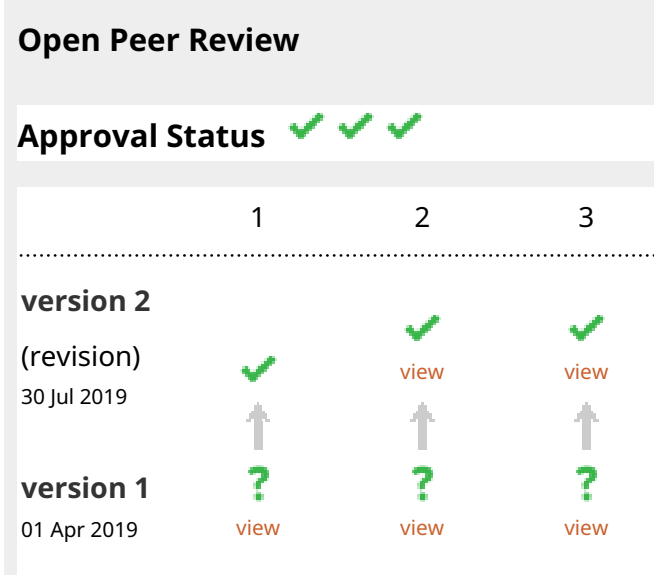

1. Pietro Mastroeni, University of Cambridge, Cambridge, UK

2. Claus-Michael Lehr, Saarland University, Saarbrücken, Germany Saarland University, Saarbrücken, Germany Patrick Carius, Helmholtz Centre for Infection Research (HZI), Saarland University, Saarland, Germany

Saarland University, Saarbrücken, Germany

3. Robert L Davies ID), University of Glasgow, Glasgow, UK

Any reports and responses or comments on the article can be found at the end of the article. 


\section{NC $3 R^{s}$}

This article is included in the NC3Rs gateway.

Corresponding author: Diane Lee (diane.lee@surrey.ac.uk)

Author roles: Lee D: Conceptualization, Data Curation, Formal Analysis, Investigation, Methodology, Project Administration, Resources, Validation, Visualization, Writing - Original Draft Preparation, Writing - Review \& Editing; Chambers M: Conceptualization, Funding Acquisition, Methodology, Project Administration, Supervision, Writing - Review \& Editing

Competing interests: No competing interests were disclosed.

Grant information: This study was supported by a strategic grant (NC/M002047/1), awarded by the National Centre for the Replacement, Refinement and Reduction of Animals in Research (NC3Rs).

Copyright: ( 2019 Lee D and Chambers M. This is an open access article distributed under the terms of the Creative Commons Attribution License, which permits unrestricted use, distribution, and reproduction in any medium, provided the original work is properly cited.

How to cite this article: Lee $D$ and Chambers M. A bilayer tissue culture model of the bovine alveolus [version 1; peer review: 3 approved with reservations] F1000Research 2019, 8:357 https://doi.org/10.12688/f1000research.18696.1

First published: 01 Apr 2019, 8:357 https://doi.org/10.12688/f1000research.18696.1 


\section{Research highlights}

Scientific benefits:

- Removes the requirement to conduct multiple in vivo studies.

- Immortalisation of cells allows consistency of data between studies.

- Easy set-up allows studies which cannot feasibly be performed in live animal models.

- Allows first-line investigations of specific disease pathways in vitro, hence is suited to drug discovery screens and toxicology studies.

\section{Rs benefits:}

- Provides an alternative to in vivo experiments on bovine respiratory diseases, negating mild-moderate invasive procedures in up to 100 cows per year (UK) used in bovine respiratory studies, approximately 40 of which will be used in BTB vaccine studies (Annual Statistics of Scientific Procedures on Living Animals for Great Britain, 2017)

\section{Practical benefits:}

- Enables users to obtain representative alveolar bilayers with desirable physiological and structural features of the native bovine alveolus within 3 weeks, rather than months, as in the case of in vivo studies.

- Immortalised cell lines facilitate reproducibility and comparisons with previously published literature.

- Cost effective compared to performing similar experiments in vivo.

- Enables researchers without animal facilities to study bovine respiratory diseases.

\section{Current applications:}

- The immortalised cell lines are suitable for studies involving monocultures of alveolar type II cells, whilst the bilayer may be used for transport studies of candidate pathogens, drug molecules, vaccines and interactions thereof.

- Currently used by researchers to study early host-pathogen interactions of Mycobacterium bovis and the live attenuated vaccine Bacillus Calmette-Guérin (BCG) in conjunction with peripheral blood mononuclear cells.

\section{Potential applications:}

- The bilayer model could potentially incorporate bovine macrophages and also be used to investigate the role of surfactant proteins in innate immunity.

- Sets the standard to recapitulate structural and functional features for future in vitro models of the alveolus.

- The bilayer alveolus model may be translatable to other species, with minor modifications.

\section{Introduction}

The lung is a complex organ, lined in its entirety by specialised epithelium. The most distal region of the lung consists of the alveoli, designed primarily for efficient gas exchange and arranged in clusters or acini ${ }^{1}$. The alveolar epithelium is composed of two types of cell; alveolar type I (ATI) and alveolar type II (ATII). Alveolar type I cells cover $90 \%$ of the alveolar surface ${ }^{2}$, despite only constituting in the region of $7 \%$ of the epithelium by numbers ${ }^{3}$. This can be attributed to the elongated squamous cell morphology of the ATI, which spreads over a large surface area and lies in close proximity to capillary endothelial cells.
This lends the ATI to its primary role of gas exchange and enables the regulation of physiological solute transport between the alveolus and the circulatory system ${ }^{4}$. Previous studies have provided evidence for the role for ATI cells in fluid homeostasis of the alveolar compartment, with the finding that sodium ions are transported via the epithelial sodium channel $(\mathrm{ENaC})$, using active ion transport ${ }^{5}$.

The ATI cell is terminally differentiated, being derived from the alveolar type II (ATII) cell. Unlike the former, the ATII cell is compact and 'cuboidal'. Early studies performed in simians and rodents generated evidence to suggest that ATII cells expressing surfactant protein $\mathrm{C}$ are the main progenitor cells of the alveolar epithelium ${ }^{6-8}$. This role was cemented by the findings of later research, including lineage tracing studies ${ }^{9}$ and morphological characterisation ${ }^{10}$. Proliferation of the ATII cell is normally relatively slow compared to other epithelial cells; however ATII hyperplasia has been reported in response to injury, such as that inflicted by the chemotherapeutic agent bleomycin, providing further evidence that ATII cells are the main progenitor of the lung ${ }^{11}$.

The close proximity of alveolar type I epithelial cells to the neighbouring capillary endothelial cells forms a highly gas permeable bilayer barrier across which gas exchange occurs. The structural integrity of the alveolus is maintained during its expansion and contraction by the formation and continuous secretion of a phospholipid-rich film (pulmonary surfactant) from ATII cells that spreads and covers the alveolar epithelial cell surface.

Perhaps most pertinent to the study of host-pathogen interactions is the role of ATII cells in innate immunity, protecting the lungs against respiratory infection. The ATII cell was first coined as the 'defender of the alveolus' by Mason and Williams in $1977^{12}$, following numerous studies into the phospholipid content of the surfactant secreted by primary ATII. As with mucus of the upper airways, the composition of surfactant varies according to disease status ${ }^{13,14}$. In particular, surfactant protein D (SP-D) has been hallmarked as a biomarker for pulmonary disease on account of its variability when quantified from bronchoalveolar lavage (BAL) or serum ${ }^{15}$. Along with surfactant protein A (SP-A), SP-D has been found to bind to viruses, bacteria, yeast and fungi. Both act as opsonins, thus increasing the pathogen's susceptibility to phagocytosis ${ }^{16-19}$.

It follows that further study of host-pathogen interactions of pathogens with ATII cells is critical to advances in the field. Costs, low throughput and ethical concerns are all limitations of in vivo models. In addition, early events at the host-pathogen interface cannot be studied easily in vivo, due to the transient nature of such early events. These limitations may be overcome by in vitro systems; however, few systems exist that accurately reproduce the structural complexity of the in vivo environment, particularly for non-human species. A human bilayer model of the alveolus was first described in $1999^{20}$ and was used to study early events in Mycobacterium tuberculosis infection. However, no equivalent in vitro bilayer model of the bovine alveolus is available to enable comparative studies between species, 
according to a search of the PubMed database using the terms, 'bovine', 'alveolus', 'bilayer' and 'model' (November 2018). In vivo models of $M$. bovis and $M$. tuberculosis infection result in 'non-recovery' of subjects and thus raise strong ethical considerations ${ }^{21}$. Cattle are natural hosts of $M$. bovis and are therefore one of the target species (alongside wildlife reservoirs such as badgers and wild boar) for strategies aimed at the study and control of bovine TB. It follows that the most relevant host-pathogen interaction studies would be performed by experimental infection of cattle. Furthermore, the close relationship of $M$. bovis to $M$. tuberculosis ${ }^{21}$ gives rise to synergy in the efforts to find novel vaccines and therapeutic interventions to control human and bovine TB. For example, vaccines which were developed for use in humans have been evaluated in the bovine $M$. bovis live animal model with reported success, whilst immune responses and reaction to therapeutic strategies are also comparable ${ }^{22-24}$. The relatively large size of cattle, however, presents a major challenge. They require particularly specialist husbandry and housing at biosafety level 3 containment, which counter the advantages of frequent and sequential sample collection and infringe upon the 'Five Freedoms', as defined by the Farm Animal Welfare Council ${ }^{25}$.

Continuous epithelial cell lines offer the advantage of reduced inter-experiment variability, extended proliferative capacity and better suitability for high-throughput screening. Such a cell line was generated from bovine ATII cells by Su et al. $(2013)^{26}$. However, upon enquiry, this was found to be no longer available. We have therefore developed a simple method of isolation for ATII cells ${ }^{27}$ and generated two new cell lines, the bovine alveolar type II (BATII) and the bovine type 2 alveolar epithelial (B2AE) cell lines. These ATII derived cells have been integrated into an in vitro tissue culture bilayer model, with bovine pulmonary arterial endothelial cells (BPAECs). Cultured at an air-liquid interface, this bilayer recreates the fundamental elements of the bovine pulmonary alveolus.

Our model advances the replacement of cattle by providing a readily available and reproducible means to study fundamental events following infection of the bovine lung with virulent pathogens that cannot be conducted currently in vitro. The model is also amenable to translational and applied research, screening and toxicity studies, especially involving zoonotic pathogens, such as $M$. bovis and $M$. tuberculosis, or respiratory syncytial virus, the human and bovine strains of which are closely related. The ease of set up and small footprint per experiment also lends the model well to the generation of pharmacological data for novel therapies targeted at respiratory disease or topical agents delivered via inhalation. This applies to diseases such as bovine respiratory disease (BRD), for which new antimicrobial therapies are urgently needed in order to develop therapeutic strategies and perform pharmacokinetic studies ${ }^{28}$. In the UK alone, the Annual Statistics of Scientific Procedures on Living Animals (2016) reports that a total of 95 procedures were performed on live cattle for respiratory research ${ }^{29}$. We can, therefore, propose with confidence that upwards of this number could potentially be replaced, per year, globally.

\section{Methods}

Isolation of alveolar type II (ATII) epithelial cells

The isolation procedure is outlined in detail by Lee et al. $(2018)^{30}$. All efforts were made to ameliorate animal suffering. This was achieved in the current study by performing the isolation procedure on tissue sourced from freshly slaughtered cattle less than 24 months of age at a local abattoir facility, under existing licensed slaughter procedures. Details of the reagents required for isolation and culture of ATII cells may be found in Table 1. A $5 \mathrm{~cm}^{3}$ piece of distal right lung was taken for disease surveillance. Tissue was dissected into pieces no greater than $3 \mathrm{~mm}^{3}$ and washed in Dulbecco's Phosphate Buffered Saline (DPBS) containing $100 \mathrm{U} / \mathrm{mL}$ each of penicillin and streptomycin, with five repetitions, with a further two washes in DPBS containing the same concentration of penicillin and streptomycin as well as $2 \mathrm{mM}$ EDTA. Digestion was carried out for 30 minutes at $37^{\circ} \mathrm{C}$ in DPBS containing $100 \mathrm{U} / \mathrm{mL}$ each of penicillin and streptomycin, $0.008 \%$ (w/v) elastase (Fisher Scientific, UK), $0.2 \%$ (w/v) collagenase (Fisher Scientific), $0.005 \%$ (v/v) DNAse Type I (2000 KU/mL; Sigma, St.Louis, MI, USA) and $0.05 \%(\mathrm{w} / \mathrm{v})$ trypsin (Gibco). Enzymatic activity was neutralised with an equal volume of Dulbecco's modified Eagle Medium/Ham's F12 (DMEM/F12) (Gibco) containing $25 \%$ FBS (heat-inactivated, Gibco) and $0.01 \%(\mathrm{v} / \mathrm{v})$ DNAse I. The cell suspension was filtered sequentially through 100, 50 and $25 \mu \mathrm{m}$ filters (Biodesign ${ }^{\mathrm{TM}}$, distributed through Fisher Scientific) and spun at $300 \times g$ for 10 minutes at room temperature, before resuspending in 1:1 DMEM/F12/Small Airway Growth Medium (SAGM) (Lonza, UK), $5 \%$ FBS and $0.025 \%$ (v/v) DNAse I.

The cell suspension was overlaid onto petri dishes coated with bovine $\operatorname{IgG}\left(5 \mu \mathrm{g} / \mathrm{mL}\right.$; Sigma Aldrich), for 1 hour at $37^{\circ} \mathrm{C}$, rocking after 30 minutes to redistribute non-adhered cells. Nonadherent cells were removed with the supernatant and spun at $300 \times g$ for 5 minutes. The resulting pellet was resuspended in $4 \%$ Percoll $^{\mathrm{TM}}$ solution (Sigma Aldrich) and overlaid onto a gradient consisting of $30 \%$ 'heavy' Percoll Percoll ${ }^{\mathrm{TM}}$. Gradients were spun at $400 \times g$ for 20 minutes at $4{ }^{\circ} \mathrm{C}$. Enriched ATII cells were identified as a band at the 10-30\% interface. These were removed and washed in DPBS containing $100 \mathrm{U} / \mathrm{mL}$ each of penicillin and streptomycin, resuspended in SAGM, plated onto 6-well plates and cultured at $37^{\circ} \mathrm{C}, 5 \% \mathrm{CO}_{2}$.

\section{Immortalisation procedure}

Details of the reagents required for immortalisation of ATII cells may be found in Table 1. ATII cells were immortalised using lentivirus particles in two ways. The BATII cell line was generated by transduction with particles encoding the catalytic subunit of human telomerase (hTERT) and Simian Virus 40 large $\mathrm{T}$ antigen (SV40), whilst the B2AE utilised hTERT and the proto-oncogene B cell-specific Moloney murine leukemia virus integration site 1 (Bmi1). SV40 lentivirus was purchased as a ready to use particle suspension (AMS Biotechnology (Europe) Ltd, Abingdon, UK). To generate hTERT and Bmi1 lentiviral particles, the hTERT (human open reading frame clone pENTR221 IOH 36343) and Bmi1 (human open reading frame clone pENTR221 IOH13688) were purchased as Entry 
Table 1. List of reagents required for isolation of alveolar type II cells, generation of lentivirus and assembly of bilayer model.

\begin{tabular}{|c|c|c|}
\hline Reagent & Supplier & Supplier \# \\
\hline Endothelial Growth Medium (EGM-2) & Lonza & CC-3162 \\
\hline Small Airway Growth Medium Bulletkit & Lonza & CC-3118 \\
\hline DPBS Ca2+/Mg2+ free & Gibco & 12037539 \\
\hline Recovery Cell Freezing Medium & Invitrogen & 12648010 \\
\hline $0.25 \%$ trypsin/0.05 \% EDTA & Life technologies & 25200056 \\
\hline Trypan Blue & Life technologies & 15250061 \\
\hline Transwell-CLEAR ${ }^{\text {TM }} 8 \mu \mathrm{m}, 6.5 \mathrm{~mm}$ & Corning & 3422 \\
\hline Dextran Blue 2000 & Sigma Aldrich & D5751 \\
\hline Formaldehyde solution & Sigma Aldrich & 47608 \\
\hline Goat serum & Sigma Aldrich & S26-M \\
\hline Triton X-100 & Sigma Aldrich & X100 \\
\hline Prolong $®$ Gold Antifade reagent with DAPI & Thermo Fisher & P36941 \\
\hline Vectashield Hardset mounting medium with phalloidin (TRITC) & Vector Laboratories & $\mathrm{H}-1600$ \\
\hline Prolong ${ }^{\circledR}$ Gold Antifade reagent with DAPI & Thermo Fisher & P36941 \\
\hline Vectashield Hardset mounting medium with phalloidin (TRITC) & Vector Laboratories & $\mathrm{H}-1600$ \\
\hline ViraPower ${ }^{\mathrm{TM}}$ II Lentiviral Gateway ${ }^{\circledR}$ Expression Kit & Invitrogen & K367-20 \\
\hline Gateway Cloning Technology system & Invitrogen & $12535-029$ \\
\hline Opti-MEM I & Gibco & 31985070 \\
\hline Lipofectamine 2000 Transfection Reagent & Invitrogen & 31985062 \\
\hline Penicillin/Streptomycin $10000 \mathrm{U} / \mathrm{mL}$ & Gibco & 11548876 \\
\hline EDTA & Fisher Scientific & 10030140 \\
\hline Porcine pancreas elastase & Fisher Scientific & 15484279 \\
\hline Deoxyribonuclease I from bovine pancreas (DNAse Type I) & Sigma Scientific & D5025 \\
\hline Trypsin $0.25 \%$ & Gibco & 11560626 \\
\hline Collagenase Type I Clostridium histolyticum & Fisher Scientific & 15434789 \\
\hline Matrix Filter Cell MicroSieve 100 mm pore & Fisher Scientific & 12684787 \\
\hline Matrix Filter Cell MicroSieve 50 mm pore & Fisher Scientific & 12924257 \\
\hline Matrix Filter Cell MicroSieve 25 mm pore & Fisher Scientific & 12944257 \\
\hline IgG from bovine serum & Sigma Aldrich & 15506 \\
\hline Tris (hydroxymethylamine) methylamine & Fisher Scientific & 10274300 \\
\hline Percoll & Sigma Aldrich & P1644 \\
\hline Foetal bovine serum, heat inactivated & Gibco & $10270-106$ \\
\hline Dulbecco's modified Eagle Medium/Ham's F12 (DMEM/F12) & Gibco & $11320-074$ \\
\hline SV40 Lentivirus particles & AMS Biotechnology & LVP557-GP \\
\hline Ultimate Human Open Reading Frame (HORF) Clone TERT & Invitrogen & HORF01-IOH36343 \\
\hline Ultimate Human Open Reading Frame (HORF) Clone Bmi1 & Invitrogen & HORF01-IOH13688 \\
\hline Bovine pulmonary arterial endothelial cells (BPAECs) & ECACC & 86123101 \\
\hline Nunc Lab-Tek II 8 chamber coverglass slides & Thermo Fisher & Z734853 \\
\hline
\end{tabular}


Vectors (Invitrogen Life Sciences, Carlsbad, CA, USA). The gene of interest was sub-cloned into a destination vector, in an LR Clonase ${ }^{\mathrm{TM}}$ recombination reaction using the Gateway Cloning Technology system (Invitrogen Life Sciences). This resulted in pLenti6-hTERT and pLenti6-Bmil expression vectors, or 'expression clones'. The expression vectors were transformed into chemically competent One Shot Stbl3 E. coli, provided as a component of the Gateway Cloning Technology System. Insert integrity for both expression vectors was assessed by restriction enzyme digestion (XhoI) and sequencing. The latter was performed using primer sequences designed using the Primer-BLAST tool ${ }^{31}$, generating primers directed at internal and flanking sites (Table 2) in the expression vector.

Live lentivirus particles were generated according to the protocols described in the Invitrogen Life Sciences ViraPower ${ }^{\mathrm{TM}}$ II Lentiviral Gateway ${ }^{\circledR}$ Expression Kit (Invitrogen Life Sciences). Briefly, $3 \mu \mathrm{g}$ of pLenti6-hTERT or pLenti6-Bmil expression vector was mixed with $9 \mu \mathrm{g}$ Virapower ${ }^{\mathrm{TM}}$ packaging mix in $1.5 \mathrm{~mL}$ Opti-MEM I medium (Invitrogen Life Sciences). This was added to $36 \mu \mathrm{L}$ Lipofectamine $^{\mathrm{TM}} 2000$ transfection reagent (Invitrogen Life Sciences) (pre-diluted in $1.5 \mathrm{~mL}$ Opti-MEM I). The DNALipofectamine complexes were added to a $10 \mathrm{~cm}$ tissue culture treated plate containing $5 \mathrm{~mL}$ of Opti-MEM I/10 \% FBS. To this, $6 \times 10^{6} 293 \mathrm{FT}$ producer cells (supplied with the kit) were added to $5 \mathrm{~mL}$ Opti-MEM I/10 \% FBS, following Invitrogen's reverse transfection protocol. Lentiviral particles were harvested as supernatant at 24,48 and 72 hours post transfection and combined, before centrifugation at $300 \times g$ for 15 minutes to pellet cell debris. The supernatant was then filtered through a $0.45 \mu \mathrm{m}$ PVDF filter and centrifuged at 20,000 rpm, using a $\mathrm{TH}-641$ rotor in a Sorvall WX80+ ultracentrifuge for 90 minutes at $4{ }^{\circ} \mathrm{C}$, to pellet viral particles.

Viral titre was determined using the HeLa cell line (p2 after receipt) according to the Virapower ${ }^{\mathrm{TM}}$ protocols and recommendations, using dilutions at $10^{-2}, 10^{-3}, 10^{-4}, 10^{-5}$ and $10^{-6}$. HeLa cells were seeded at $2 \times 10^{5}$ cells/well in a 6-well plate, in DMEM/10 \% FBS/1 $\times$ non-essential amino acids ('complete medium', all Gibco). On the day of transduction (24 hours after seeding), cell supernatant was removed and the viral supernatant

Table 2. Primer sequences used to confirm expression vector integrity. Primers for the internal sequencing segments were designed using the Primer-BLAST online tool, whilst the external CMV and V5 (C-terminal) sequences were provided by Invitrogen.

\begin{tabular}{|l|l|l|}
\hline Bmi1 Internal & FWD & ATCCCCACCTGATGTGTGTG \\
\hline Bmi1 Internal & REV & TGTACAAGAAAGCTGGGTTC \\
\hline hTERT Internal pair 1 & FWD & CGACGTCTTCCTACGCTTCA \\
\hline hTERT Internal pair 1 & REV & CAAGAAAGCTGGGTTCTAGTCCA \\
\hline hTERT Internal pair 2 & FWD & GGAACCATAGCGTCAGGGAG \\
\hline hTERT Internal pair 2 & REV & GCTTCCCCAGGGAGATGAAC \\
\hline CMV & FWD & CGCAAATGGGCGGTAGGCGTG \\
\hline V5 (C-term) & REV & ACCGAGGAGAGGGTTAGGGAT \\
\hline
\end{tabular}

dilutions, prepared in complete medium, were added directly to the cell cultures ( $1 \mathrm{~mL}$ total culture volume). Medium only was added to a 'mock' well, used to confirm cell death in the presence of the selection antibiotic, blasticidin. To each well, $6 \mu \mathrm{g}$ of Polybrene ${ }^{\circledR}$ transfection reagent (Sigma Aldrich) was added. Cells were returned to the incubator and cultured at $37^{\circ} \mathrm{C}, 5 \%$ $\mathrm{CO}_{2}$ for 24 hours. Medium containing the viral supernatant was then replaced with $2 \mathrm{~mL}$ complete culture medium and the plates returned to the incubator for a further 24 hours. At 48 hours after transduction, blasticidin was added to all wells except untreated controls at a concentration of $10 \mu \mathrm{g} / \mathrm{mL}$. Medium containing blasticidin was replaced every 3-4 days, until 14 days, when all cells were dead in the mock well and discrete antibiotic-resistant colonies could be seen in wells transduced with viral supernatant. These were counted following visualisation with $1 \%$ crystal violet solution (Sigma Aldrich) and titre determined by averaging the counts of two wells, following correction for dilutions. Titred virus was stored at $-80^{\circ} \mathrm{C}$ until use.

Primary ATII cells were immortalised at p1, five days after isolation. Cells were seeded into four wells of a 24-well plate at a density of $0.5 \times 10^{5}$ cells $/ \mathrm{mL}, 0.5 \mathrm{~mL}$ per well, in complete SAGM, without antibiotics. At 24 hours, SV40 and hTERT lentiviral particles were added simultaneously at a multiplicity of infection (MOI) of 10 (for each virus), in $0.5 \mathrm{~mL}$ SAGM, again without antibiotics. At 24 hours post infection, the media was replaced with fresh SAGM $(1 \mathrm{~mL})$. Cultures were fed every 2-3 days with SAGM and passaged accordingly, alongside primary ATII cells for comparison and grown without selection, monitoring morphology, proliferation rate and karyotype.

\section{Growth curves}

Growth curves for the immortalised cell lines were performed at passages 2, 10 and 18, comparing them with those of primary ATII cells at passage 2, using the CellTitre $96 \AA{ }^{\circledR} \mathrm{AQ}_{\text {uеous }}$ One Proliferation Assay (Promega, Madison, WI, USA). Cell number and viability were determined by trypan blue exclusion (cells displaying uptake of trypan blue were considered non-viable) using a TC-20 automated cell counter (BioRad, Hercules, CA, USA). For each cell type/passage, cells were resuspended to a final concentration of $0.5 \times 10^{5}$ cells $/ \mathrm{mL}$ in SAGM. An aliquot (100 $\mu \mathrm{L}, 5000$ cells) was dispensed into three wells of a 96-well plate (x 9 plates), before incubation in a humidified, $5 \%$ $\mathrm{CO}_{2}$ atmosphere at $37^{\circ} \mathrm{C}$. At 24 hours, one plate was removed. To each well, $20 \mu \mathrm{L}$ of CellTiter 96® AQueous One Solution Reagent was added, returning the plate to the incubator for 1 hour. Absorbance was then measured at $490 \mathrm{~nm}$, using the CLARIOstar® 96-well plate reader (BMG Labtech, Ortenburg, Germany). The assay procedure was repeated for the remaining time points. Resulting absorbances were entered as interpolated values against a reference curve generated from seeding pre-determined cell numbers in the same format and performing the assay after a 1 hour incubation period.

\section{Karyotyping}

To determine genetic integrity and characterise the stability of the immortalised cell lines, a metaphase chromosomal spread 
was carried out to ascertain karyotype of the BATII cell line at passages 4, 14 and 23 and of the B2AE cell line at passages 7, 12 and 22. The preparation of each spread was based on the protocol published by Campos et al..$^{32}$, with some deviations. Briefly, BATII, B2AE or wild-type ATII cells at the relevant passage were revived from liquid nitrogen stores and cultured for 48 hours in SAGM, in a humidified, $5 \% \mathrm{CO}_{2}$ atmosphere at $37^{\circ} \mathrm{C}$. Cells were then treated with Colcemid ${ }^{\mathrm{TM}}$ (Sigma Aldrich) at a final concentration of $0.2 \mu \mathrm{g} / \mathrm{mL}$ in SAGM. Cells were returned to the incubator for $4 \mathrm{~h}$, before trypsinisation with $0.25 \%$ trypsin/0.05 \% EDTA (Gibco/Invitrogen Life Sciences) for 5 minutes at $37^{\circ} \mathrm{C}$. After trypsin neutralisation, cells were centrifuged at $122 \times g$ for 5 minutes. The supernatant was discarded and $5 \mathrm{~mL}$ pre-warmed $\left(37^{\circ} \mathrm{C}\right)$ hypotonic solution $\left(\mathrm{KCl} 75 \mathrm{mM}_{(\mathrm{aq})}\right)$ was added in a two-stage process: $3 \mathrm{~mL}$ was added to the tube in an inclined position, whilst rotating the tube to mix cells, followed by the remaining $2 \mathrm{~mL}$ to the upright tube. The cells and hypotonic solution were placed at $37^{\circ} \mathrm{C}$ for 15 minutes to allow swelling. To fix cells, three drops of room temperature fixative solution (freshly prepared methanol/glacial acetic acid 3:1) were added to the tube, followed by inversion to mix and centrifugation (without brake) at $122 \times g$ for 5 minutes. The supernatant was again discarded, leaving $200 \mu \mathrm{L}$ hypotonic solution. Fixative solution $(3 \mathrm{~mL})$ was added to the tube at an incline, rotating as before, followed by a further $2 \mathrm{~mL}$ to the tube wall, to wash attached cells down. The tube was stored upright overnight at $4^{\circ} \mathrm{C}$, before centrifugation as before. Supernatant was again discarded, leaving $200 \mu \mathrm{L}$, and the pellet was resuspended by flicking the tube. Fixative solution $(5 \mathrm{~mL})$ was added as before and the centrifugation step repeated, again leaving $200 \mu \mathrm{L}$ supernatant and resuspending by flicking the tube. An aliquot of each sample $(20 \mu \mathrm{L})$ was spread onto a microscope slide pre-cleaned in $6 \mathrm{M} \mathrm{HCl}$, moving the pipette tip across the surface during dispensing. The slide was then passed through steam (face up). Slides were mounted with coverslips in Vectorshield Hardset with DAPI (Vector Laboratories, Burlingame, CA, USA) and examined under a fluorescence microscope to determine karyotype.

\section{Coating of plastic and Transwell inserts with Matrigel}

To test the effects of an extracellular matrix on the culture of ATII cells, we coated tissue culture in plastic and also permeable inserts in a $10 \%$ solution of growth factor reduced Matrigel ${ }^{\mathrm{TM}}$ (356230, Corning). Matrigel ${ }^{\mathrm{TM}}$ was thawed on ice overnight in a cold room and kept on ice throughout the procedure. Pre-cooled SAGM was stored on ice and Matrigel ${ }^{\mathrm{TM}}$ added to a final concentration of $10 \%$. Using chilled pipette tips, the solution was used to coat either $12 \mathrm{~mm}$ diameter Transwell ${ }^{\mathrm{TM}}$ CLEAR $3.0 \mu \mathrm{m}$ pore size PET inserts (3462, Corning, New York, US) or the surface of wells in a 24-well tissue culture plate (3337, Corning) $\left(50 \mu \mathrm{L}\right.$ per $\left.\mathrm{cm}^{2}\right)$. Coating was performed overnight at $2-8^{\circ} \mathrm{C}$ and stored until use (up to 2 weeks). Coated surfaces were gently washed once with SAGM to remove excess Matrigel $^{\mathrm{TM}}$.

\section{Culture conditions of BPAEC}

Bovine pulmonary artery endothelial cells (BPAECs) were purchased from the European Collection of Authenticated Cell
Cultures (ECACC) (Salisbury, UK) and cultured in endothelial growth medium (EGM-2 Bulletkit) (Lonza, UK). Cells were used between passages 3 and 10 only.

\section{Assembly of bilayer}

A schematic of the bilayer assembly is shown in Figure 1. BPAECs were revived from liquid nitrogen and cultured to $80 \%$ confluence in EGM-2. Cells were trypsinised using $0.25 \%$ trypsin/0.05 \% EDTA and neutralised using an equivalent volume of DMEM/10 \% FBS, before seeding onto the apical surface of $6.5 \mathrm{~mm}$ diameter Transwell-CLEAR ${ }^{\mathrm{TM}} 8 \mu \mathrm{m}$ pore size permeable membranes in a 24 -well plate, at a density of $2 \times 10^{4}$ cells/insert, (approximately $6.5 \times 10^{4}$ cells $/ \mathrm{cm}^{2}$ ). EGM-2 $(600 \mu \mathrm{L})$ was added to the basolateral chamber of each well. BPAECs were cultured for 5-7 days, replacing EGM-2 in the basolateral chamber and removing apical medium which had seeped through from the basolateral side of the membrane. BATII (or B2AE) cells were revived 3 days after BPAEC and cultured in SAGM without antibiotics. On the day of seeding, cells were trypsinised, resuspended in EGM-2 and counted, before seeding on top of the BPAEC layer at a density of $2 \times 10^{4}$ cells/insert, as before. For histology, additional bilayers were seeded onto $12 \mathrm{~mm}$ diameter TranswellCLEAR $^{\mathrm{TM}} 0.4 \mu \mathrm{m}$ pore size (also $6.5 \times 10^{4}$ cells $/ \mathrm{cm}^{2}$ for each cell line), adding $1.5 \mathrm{~mL}$ EGM-2 basolaterally. In each case, the bilayer was returned to the incubator for 2 hours to allow for attachment, after which the apical medium was removed and the cells cultured at air-liquid interface for 14 days, feeding every 2-3 days basolaterally $(600 \mu \mathrm{L})$ and removing any medium on the apical surface. Monolayers were also prepared for each cell type, using the same seeding densities and culture methods/feeding intervals for comparison.

\section{Measurement of cell layer integrity}

The formation of tight junctions was assessed for monolayers of both cell types and bilayers in three ways. Firstly, each mono (BPAEC or BATII only) or bilayer was visually assessed, observing the apical surface by eye to estimate coverage by EGM-2 which had come through from the basolateral chamber.

Secondly, trans-epithelial electrical resistance (TEER) was measured between the time of seeding until the day of harvest. TEER values were measured using an EVOM2 Voltohmmeter with STX-2 chopstick electrodes (World Precision Instruments, Stevenage, UK) immediately before the medium was exchanged. For measurements, $0.5 \mathrm{~mL}$ and $1.0 \mathrm{~mL}$ of medium were added to the apical and basolateral chambers, respectively, allowing the medium to equilibrate to $37^{\circ} \mathrm{C}$ before measurements were performed in triplicate. All values were converted to $\mathrm{Ohms} / \mathrm{cm}^{2}$ using Equation 1.

Final TEER $\left(\Omega / \mathrm{cm}^{2}\right)=\operatorname{NetTEER}(\Omega) \times$ Area of Transwell insert $\left(\mathrm{cm}^{2}\right) \quad$ (Equation 1)

The third method of determining layer integrity utilised the dextran permeability method, as outlined by Birkness et al. (1999) ${ }^{20}$. A $10 \mathrm{mg} / \mathrm{mL}$ solution of Dextran Blue 2000 (DB2000; Sigma Aldrich) was prepared in DPBS, alongside standard solutions of $7.5,5.0,3.75,2.5,1.25,0.625,0.3125$ and $0.156 \mathrm{mg} / \mathrm{mL}$. DPBS $(600 \mu \mathrm{L})$ was added to each well of a fresh 24 -well plate. 

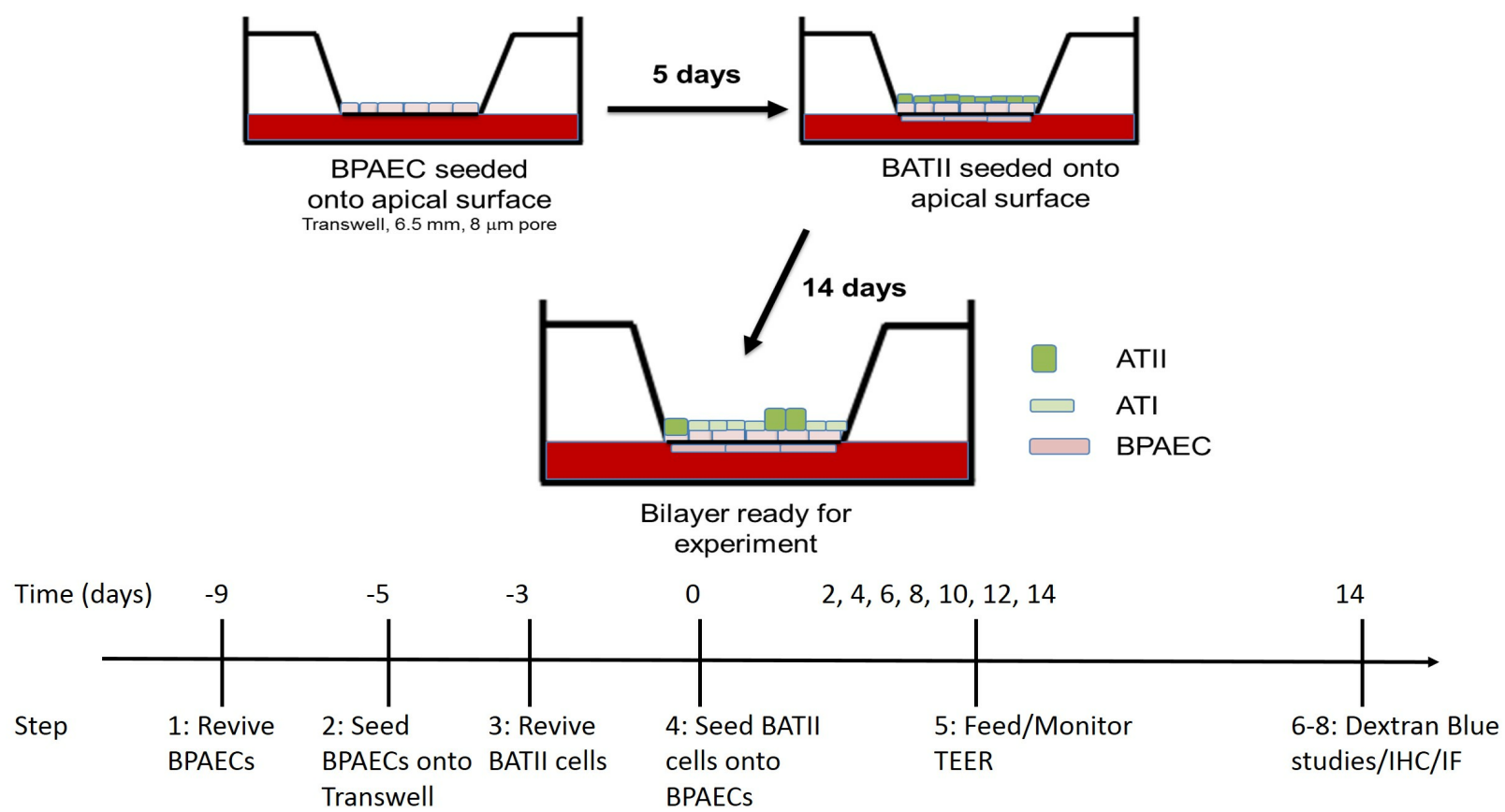

Figure 1. Schematic of the procedure used to set up a 14-day bilayer model. Bovine pulmonary arterial endothelial cells (BPAECs) are seeded onto the apical surface of the insert membrane and cultured for 5 days. The immortalised Bovine Alveolar Type II (BATII) epithelial cells are then overlaid onto the BPAECs and the bilayer cultured for 14 days as outlined in the methods section. Also shown is a timeline detailing the $\operatorname{step}(\mathrm{s})$ required at each timepoint.

Inserts containing cells were removed one by one from the original plate, removing any apical medium, and transferred to the fresh plate. DB2000 (100 $\mu \mathrm{L}$ of $10 \mathrm{mg} / \mathrm{mL})$ was added to the apical surface of each insert during the transfer. The plate was then placed at $37^{\circ} \mathrm{C}, 5 \% \mathrm{CO}_{2}$, for 1 hour. A blank insert was treated in the same way. An empty well had $600 \mu \mathrm{L}$ DPBS added, followed by $100 \mu \mathrm{L}$ of $10 \mathrm{mg} / \mathrm{mL}$ DB2000 in DPBS (total volume $700 \mu \mathrm{L})$. This was designated 'no membrane control'. At the end of the incubation, $600 \mu \mathrm{L}$ was removed from the basolateral compartment and read at $630 \mathrm{~nm}$ on a spectrophotometer, alongside the prepared standards. An aliquot $(60 \mu \mathrm{L})$ was taken from apical solutions and diluted in $540 \mu \mathrm{L}$ DPBS (a ten-fold dilution), before reading at $630 \mathrm{~nm}$. Unknown values were extrapolated from a linear regression of the standard curve.

\section{Microscopy}

For characterisation of the novel cell lines, BATII and B2AE cells were seeded onto Nunc Lab-Tek II 8 chamber coverglass slides (Thermo Fisher). Cells were seeded at $4 \times 10^{4}$ cells per chamber and cultured for 72 hours. Slides were then washed with DPBS and fixed in $4 \%$ PFA at room temperature for 15 minutes, before permeabilisation by washing in an immunofluorescence wash buffer (IF buffer) (Table 3) containing $0.1 \%$ triton X-100 for 15 minutes. Blocking was performed for 1 hour at room temperature in DPBS/ $5 \%$ normal goat serum/ $0.1 \%$ triton $\mathrm{X}-100$. Primary antibodies were diluted in blocking buffer, applied to cells and incubated overnight at $4^{\circ} \mathrm{C}$. Cells were rinsed three times with IF buffer and secondary antibody applied for 1 hour at room temperature in the dark. Cells were again rinsed three times with IF buffer and stored at $4{ }^{\circ} \mathrm{C}$ until imaging, using a Nikon Eclipse Ti confocal microscope.
For immunofluorescence (IF) analysis of bilayer cultures, inserts were washed with DPBS and processed as for coverglass monolayer cultures. Following the final wash to remove the secondary antibody, the membrane was removed from the insert using a scalpel blade, then mounted in Prolong ${ }^{\circledR}$ Gold Antifade reagent with 4',6-diamidino-2-phenylindole (DAPI) (Fisher Scientific) or Vectashield Hardset mounting medium with phalloidin (TRITC) (Vector Laboratories, Burlingame, CA, US) between two cover slips. Bilayers were imaged using a Nikon Eclipse Ti confocal microscope.

Primary antibodies are detailed below in Table 4. Mouse and rabbit IgG1 isotype controls were used accordingly.

For histology, fixed membranes were dehydrated sequentially in 70, 90 and $100 \%$ ethanol, for 30 minutes at each concentration. Inserts were then incubated in $100 \%$ isopropanol for 30 minutes, before transfer to molten paraffin wax $\left(65^{\circ} \mathrm{C}\right)$ for 1 hour. The membrane was then excised from the insert using a scalpel blade and embedded in paraffin, cured and sectioned at $4 \mu \mathrm{m}$. Sections were subjected to dewaxing and H\&E staining as outlined in Lee et $a l .^{30}$. Stained sections were dehydrated and mounted in DPX mounting medium (Sigma Aldrich) with a cover-slip overlaid for analysis on a Nikon Eclipse $\mathrm{Ci}$ upright microscope.

\section{Statistics}

All statistical analysis was performed using GraphPad Prism version 7.03 for Windows, GraphPad Software, La Jolla, California, USA, www.graphpad.com. Replicate numbers and number of experiments are detailed in figure legends. Dextran blue 
Table 3. Recipe for 10X Immunofluorescence (IF) buffer, used to wash and permeabilise cells. The following ingredients are added to $\sim 475 \mathrm{~mL}$ reverse osmosis water and the resulting solution buffered to $\mathrm{pH} 7.4$. Top up to $500 \mathrm{~mL}$, then store at $2-8^{\circ} \mathrm{C}$. Remove to room temperature before use and dilute $1: 10$ with reverse osmosis water.

\begin{tabular}{|l|c|c|c|}
\hline Product & Product Number & Supplier & QTY \\
\hline Sodium chloride $(\mathrm{NaCl})$ & $\mathrm{S} 9888$ & Sigma Aldrich, UK & $38 \mathrm{~g}$ \\
\hline Dibasic heptahydrate $\left(\mathrm{Na}_{2} \mathrm{HPO}_{4}\right)$ & $\mathrm{S} 9390$ & Sigma Aldrich, UK & $9.38 \mathrm{~g}$ \\
\hline Monobasic monohydrate $\left(\mathrm{NaH}_{2} \mathrm{PO}_{4}\right)$ & $\mathrm{S} 9368$ & Sigma Aldrich, UK & $2.07 \mathrm{~g}$ \\
\hline Sodium azide $\left(\mathrm{NaN}_{3}\right)$ & $\mathrm{S} 8032$ & Sigma Aldrich, UK & $2.5 \mathrm{~g}$ \\
\hline Bovine serum albumin $(\mathrm{BSA})$ & $\mathrm{A} 2153$ & Sigma Aldrich, UK & $5 \mathrm{~g}$ \\
\hline Triton X-100 & X100 & Sigma Aldrich, UK & $10 \mathrm{~mL}$ \\
\hline Tween 20 & $\mathrm{P} 1379$ & Sigma Aldrich, UK & $2.05 \mathrm{~mL}$ \\
\hline
\end{tabular}

Table 4. List of antibodies used for immunofluorescence studies.

\begin{tabular}{|c|c|c|c|c|c|c|}
\hline Antibody & $\begin{array}{l}\text { Product } \\
\text { Number }\end{array}$ & Supplier & RRID & Host & Clonality & Dilution \\
\hline Pro-surfactant Protein C (proSP-C) & ab3786 & Millipore & AB_91588 & Rabbit & polyclonal & $1: 100$ \\
\hline Cluster of differentiation 74 (CD74) & sc47742 & Santa Cruz & AB_627172 & Mouse & Pin. 1 & $1: 100$ \\
\hline Solute carrier family 34 member 2 (SLC34A2) & HPA037989 & Sigma Aldrich & AB_10670536 & Rabbit & polyclonal & $1: 100$ \\
\hline Vimentin & sc-58901 & Santa Cruz & AB_794004 & Mouse & Vim 3B4 & $1: 100$ \\
\hline Cluster of differentiation 31 (CD31) & MA3100 & Thermo Fisher Scientific & AB_223516 & Mouse & HEC7 & $1: 100$ \\
\hline Anti-Mouse IgG $(\mathrm{H}+\mathrm{L})$ FITC Conjugated & $62-6511$ & Thermo Fisher Scientific & AB_88368 & Goat & polyclonal & $1: 200$ \\
\hline $\begin{array}{l}\text { Goat Anti-Rabbit IgG }(\mathrm{H}+\mathrm{L}) \text { Texas Red } \\
\text { Conjugated }\end{array}$ & T2767 & Molecular Probes & AB_221655 & Goat & polyclonal & $1: 200$ \\
\hline
\end{tabular}

measurements (Figure 7A-B) were evaluated using a one-way ANOVA and Tukey's multiple comparisons tests. These are presented as means \pm standard deviation, where $\mathrm{n}$ represents individual inserts, selected at random by the researcher and assigned into groups (not blind). Statistical significance is denoted as $* \mathrm{p} \leq 0.05, * * \mathrm{p} \leq 0.01, * * * \mathrm{p} \leq 0.001$ and $* * * * \mathrm{p} \leq 0.0001$ (Tukey's multiple comparisons test shown). Sample size was limited by plate size and practical considerations (handling of multiple samples of this nature). We therefore performed three repeats of each experiment ( $n=3$ inserts per group) on different days, using fresh cells and inserts to ensure replicability of findings. To increase the statistical power of each test, data from identical groups of each day was first analysed using ANOVA and a Tukey's multiple comparison's test for variability, before combining replicates from each day to give a total of 9 replicates per group. Gaussian distribution was assumed for ANOVA; however, sphericity (equal variability of differences) was not and thus, the Geisser-Greenhouse correction was used.

TEER analysis was performed for the average of three readings per insert at each time point, with six inserts per group, per experiment (BATII and B2AE bilayers). Data shown is combined from three experiments performed on different days and presented as means \pm standard deviation, analysed using an unpaired t-test.

\section{Protocol}

Here we describe the step by step procedure used to set up and validate a 14-day bilayer of BATII (ATII-derived) epithelial cells with BPAEC endothelial cells on Transwell inserts. A simplified schematic of the procedure, including timeline, is found in Figure 1, whilst all reagents may be found, with their provenance, in Table 1 . In principle, the same protocol also applies to the pairing of B2AE cells in a bilayer with BPAECs; however, it should be noted that the authors have not optimised this arrangement, having chosen to focus on BATII cells for reasons outlined in the discussion.

Step 1: Revive BPAEC cells (Day -9). All stages of culture are carried out in a humidified incubator, at $37^{\circ} \mathrm{C}, 5 \% \mathrm{CO}_{2}$.

We use cells between passages 2 and 10, for consistency and to eliminate the potential for phenotypic drift at higher passages. Cells, frozen down at $1 \times 10^{6} / \mathrm{mL} / \mathrm{vial}$ in Recovery ${ }^{\mathrm{TM}}$ Cell Freezing Medium (12648010, Invitrogen), were revived from liquid 
nitrogen, seeded at a density of $2 \times 10^{6}$ cells per T75 $\mathrm{cm}^{2}$ flask in EGM-2 (CC-3162, Lonza, UK) and cultured to $80 \%$ confluence, without antibiotics*. EGM-2 media $(500 \mathrm{~mL})$ should be made up on the day of revival from liquid nitrogen, using freshly thawed Lonza bullet kit Singlequots ${ }^{\mathrm{TM}}$. After a period of one month, any remaining media of the batch should be discarded and fresh media prepared. One bottle is sufficient to maintain BPAEC cells (using $10 \mathrm{~mL}$ per $\mathrm{T} 75 \mathrm{~cm}^{2}$ flask) and also feed one 24 well plate of bilayer cultures for a total of 21 days (including the initial culture phase, consisting of BPAEC cells only). Medium is exchanged the day after seeding (day -8) and at 2 days (day -6), always ensuring that the cells have media exchanged the day before trypsinisation.

*These cells are not sensitive to penicillin and streptomycin; however, our downstream applications require the bilayer system to be antibiotic free.

Step 2: Seed BPAECs onto Transwells (Day -5). BPAEC cells are trypsinised using $3 \mathrm{~mL}$ of $0.25 \%$ trypsin/0.05\% EDTA (25200056, Life Technologies, UK) per T75 $\mathrm{cm}^{2}$ flask and neutralised using an equivalent volume of DMEM/10 \% FBS. The suspension is triturated to ensure homogeneity of the suspension, centrifuged at $300 \times g$ for 5 minutes, then resuspended in $1 \mathrm{~mL}$ EGM-2 for counting, using the TC-20 automated cell counter. This takes the form of a viability count, mixing $10 \mu \mathrm{L}$ of cell suspension with $10 \mu \mathrm{L}$ of $0.4 \%$ trypan blue (15250061, Life technologies). BPAEC cells are then seeded onto the apical surface of $6.5 \mathrm{~mm}$ diameter Transwell-CLEAR ${ }^{\mathrm{TM}} 8 \mu \mathrm{m}$ pore size permeable membranes in a 24 well plate, at a density of $2 \times 10^{4}$ cells/insert, in $100 \mu \mathrm{L}$ EGM-2 (approximately $6.5 \times 10^{4}$ cells $\left./ \mathrm{cm}^{2}\right)$. EGM-2 $(600 \mu \mathrm{L}$, the volume recommended by Corning) is added to the basolateral chamber of each well. BPAECs are cultured on the Transwell inserts for 5-7 days, replacing EGM-2 in the basolateral chamber at 2-day intervals and removing apical medium which seeps through from the basolateral side of the membrane. BPAECs do not form sufficient tight junctions to prevent media seepage - this step is simply to remove old media from the apical surface.

Step 3: Revival of BATII cells (Day -3). The BATII cell line has thus far not been karyotyped beyond passage 23 , therefore we have restricted use between p14 and p23 in our own experiments. We freeze down BATII cells at a density of $1 \times 10^{6}$ cells $/ \mathrm{mL} / \mathrm{vial}$ in Recovery ${ }^{\mathrm{TM}}$ Cell Freezing Medium (as before). BATII cells should be revived 3 days prior to seeding onto Transwell inserts and cultured in SAGM (CC-3118, Lonza) without antibiotics, seeding $1 \times 10^{6}$ cells per $\mathrm{T} 75 \mathrm{~cm} 2$ flask, to allow for the relatively high proliferation rate of these cells compared to BPAECs. As with EGM-2, SAGM should be prepared fresh using the Lonza Singlequots ${ }^{\mathrm{TM}}$ on the day of revival and any media remaining after one month discarded. BATII cells are fed the day after seeding into flasks and also the day before trypsinisation, at a volume of $10 \mathrm{~mL}$ per $T 72 \mathrm{~cm}^{2}$ flask.

Step 4: Seeding of BATII cells onto the BPAEC layer (Day 0). On the day of seeding, cells are trypsinised and neutralised as for BPAECs, resuspended in $1 \mathrm{~mL}$ EGM-2 and counted, as before. A dilution is prepared in EGM-2, at a density of $2 \times 10^{5}$ cells $/ \mathrm{mL}$. Seeding on top of the BPAEC layer is performed at a density of $2 \times 10^{4}$ cells/insert. The bilayers are then returned to the incubator for 2 hours to allow for attachment, after which the apical medium should be removed and the cells cultured at air-liquid interface (ALI) for 14 days. Cultures achieve ALI (defined as less than $25 \%$ of the insert submerged by EGM-2) from around 5 days after the seeding of BATII cells.

Step 5: Feeding and TEER monitoring (Day 2 - 14). Cultures are maintained in a humidified incubator, at $37^{\circ} \mathrm{C}, 5 \% \mathrm{CO}_{2}$, feeding every 2-3 days in the basolateral compartment only $(600 \mu \mathrm{L})$ and removing any media on the apical surface.

Technical tip: Media removal or addition is performed by tilting the plate to a $30^{\circ}$ angle and placing the tip edge against the side of the well. Additions are performed slowly. This helps the user to avoid touching the cell layers and minimises cell stress.

TEER studies are carried out from 2 days after the seeding of BATII cells onto BPAEC cells in Transwells, i.e. the generation of a bilayer. BPAECs do not form sufficient tight junctions compared to a bilayer and this this is reflected in the TEER values, when comparing bilayers or BATII monolayers to BPAEC monolayers. Measurements are acquired using the EVOM2 epithelial Voltohmmeter, with a $4 \mathrm{~mm}$ STX2 chopstick electrode (300523, World Precision Instruments Inc., US). When monitoring trans-epithelial electrical resistance (TEER), on the day of feeding, fresh EGM-2 should first be placed in the apical chamber $(500 \mu \mathrm{L})$ as well as the basolateral compartment $(600 \mu \mathrm{L})$. A blank Transwell insert is set up in another well for comparison. The nature of TEER measurement means that drift is to be expected, particularly as the plate cools down during measurement, therefore the medium should be equilibrated to temperature in situ (at least 15 minutes) before measurements are taken. Ideally, this temperature is $37^{\circ} \mathrm{C}$; however, in practice, this is difficult to achieve if a full 24 well plate is to be measured. We therefore perform 3 measurements in each well (moving from well 1 to 24 , then repeating the process twice), using chopstick electrodes which are first sterilised in $70 \%$ ethanol and rinsed in DPBS. Net TEER is calculated by subtracting the reference (blank Transwell insert only) from the measured TEER of the bilayer or monolayer sample (Equation 2). This is then converted to Final TEER by correcting the value for the area of cell growth (Equation 3).

Apical medium is removed after TEER measurements, to maintain ALI. Average TEER is plotted for each well at a particular time point. As part of our characterisation studies, the 'average of averages' (average of 3 readings taken in each replicate well, $\mathrm{n}=3$ Transwells per timepoint) for each time point were plotted between days 2 and 14 of bilayer culture, with standard deviation.

Technical tip: to keep readings as consistent as possible, hold the chopstick electrodes in the same place for each insert in a perpendicular fashion to the plate surface, with the shorter electrode in the apical compartment and both electrodes 
submerged. Avoid touching the bilayer itself, or walls of the insert, as this risks damaging the cells and generating inconsistent readings. This is even more important when using $12 \mathrm{~mm}$ diameter inserts, as variation is greater. If readings are inconsistent for a particular well, or the resistance is unexpectedly high, consider using fine grade sandpaper to carefully rub the silver tip of the electrodes (the bulbous, inward facing area of the chopsticks). No other part of the electrode should be touched the chopsticks are incredibly delicate, so store carefully and avoid creasing the wire.

$$
\begin{aligned}
& \text { Net TEER }(\Omega)=\text { Measured TEER }(\Omega)-\text { Reference TEER }(\Omega) \quad(\text { Equation 2) } \\
& \text { Final TEER }\left(\Omega / \mathrm{cm}^{2}\right)=\operatorname{Net} \operatorname{TEER}(\Omega) \times \text { Area of Transwell insert }\left(\mathrm{cm}^{2}\right) \quad(\text { Equation 3) }
\end{aligned}
$$

Step 6: Dextran Blue Studies (Day 14). Dextran blue permeability may be performed either at a single time point, as a measure of layer integrity, at multiple time points using single measurements, or at multiple time points sampling from the same well, enabling the calculation of 'apparent permeability'. In the current studies, we have been comparing bilayers with single layers of both BPAEC and BATII, therefore we have chosen to use single sampling, single time point analysis. Unlike TEER, dextran blue studies mean sacrificing the insert used; therefore, this should be allowed for when calculating replicates and so on for bilayer studies.

A $10 \mathrm{mg} / \mathrm{mL}$ stock solution should be prepared using Dextran Blue 2000 (DB2000; D5751, Sigma, MI, USA) in DPBS, alongside standard solutions of 7.5, 5.0, 3.75, 2.5, 1.25, 0.625, 0.3125 and $0.156 \mathrm{mg} / \mathrm{mL}$. Add DPBS $(600 \mu \mathrm{L})$ to each well of a fresh 24 well plate and equilibrate the plate to $37^{\circ} \mathrm{C}$ (minimum 15 minutes).

Remove inserts containing cells one by one from the original plate, removing any apical medium during the transfer. Add the dextran blue stock solution $(100 \mu \mathrm{L}$ of $10 \mathrm{mg} / \mathrm{mL})$ to the apical surface of each insert during the transfer and place the insert in the fresh plate. A blank insert is set up alongside the bilayer/ monolayer cultures and used as a no cell control, along with a well containing $600 \mu \mathrm{L}$ of DPBS and $100 \mu \mathrm{L}$ dextran blue solution at $10 \mathrm{mg} / \mathrm{mL}$, to determine extent of resistance exerted by the membrane.

Technical tip: Use two $200 \mu \mathrm{L}$ pipettes when removing medium and adding dextran blue solution. This enables the user to have one pipette set to $100 \mu \mathrm{L}$ (for dextran blue) and the other to $200 \mu \mathrm{L}$, to ensure that all apical medium is removed (if present - bilayers should have very little at 14 days).

Return the plate to $37^{\circ} \mathrm{C}, 5 \% \mathrm{CO}_{2}$ for 1 hour. At the end of the incubation, remove $600 \mu \mathrm{L}$ from the basolateral compartment and read at $630 \mathrm{~nm}$ on a spectrophotometer in a $1 \mathrm{~mL}$ volume disposable cuvette. This should be carried out alongside $600 \mu \mathrm{L}$ of the prepared standards. To allow for lower volumes in the apical compartments, we dilute an aliquot $(60 \mu \mathrm{L})$ from apical solutions in $540 \mu \mathrm{L}$ DPBS (a ten-fold dilution), before reading at $630 \mathrm{~nm}$. Unknown values may then be extrapolated from a linear regression of the standard curve and corrected for dilutions accordingly.

Step 7: IF Microscopy of whole inserts (Day 14 onwards). Cells cultured for 14 days are used for IF studies, to ensure that structural features reminiscent of the native alveolar epithelium are present, in particular a pseudostratified mix of ATII and their differentiated counterparts, ATI. At this stage, the endothelial layer of BPAECs have started to migrate through the membrane pores. This allows a more consistent contact with the underlying medium and also has the effect of providing 'anchorage'. For this reason, we do not use an ECM to coat our Transwells, although we have included the protocol in our Methods, for users who wish to culture ATII cells or cell lines as a monolayer.

Technical tips: It is possible to divide membranes to maximise output; however, in our experience, the medial area of the insert is very delicate, so caution should be exercised and a fresh scalpel or razor blade used for each membrane, rocking the blade across the membrane rather than slicing, to reduce shear forces. When probing whole inserts, this may be done in situ, adding $100 \mu \mathrm{L}$ of antibody solution to the apical side and $50 \mu \mathrm{L}$ to the underside, holding the tip against the outer edge of the vertical wall of the insert and allowing the solution to be drawn under the membrane by capillary action.

Transwell membranes are first washed three times (gently, holding the pipette against the inner wall of the insert when washing the apical surface) with DPBS. Cultures are then fixed in $4 \%$ PFA for 15 - 30 minutes at room temperature. Each membrane is then washed three times in immunofluorescence buffer (IF buffer, details in Table 2), 5 minutes per wash. This also permeabilises the cells.

Permeabilised cultures are blocked in DPBS/ $5 \%$ normal goat serum (S26-M, Sigma Aldrich)/ $0.1 \%$ triton X-100 (X100, Sigma Aldrich) for 1 hour, at room temperature. All antibody solutions are then made up in the same blocking buffer and applied to the apical and basolateral aspects of the membrane (see tips above). The plate containing the inserts are then incubated overnight at $4^{\circ} \mathrm{C}$. The next day, inserts are washed three times with IF buffer ( 5 minutes per wash at room temperature) and secondary antibody applied for 1 hour at room temperature in the dark. Secondary antibodies are applied as follows: cells are again washed three times with IF buffer (5 minutes per wash at room temperature) and the membrane removed from the insert, using a fresh scalpel blade. Resting the inverted insert on a flat surface, run the leading edge of the blade around the circumference of the insert, turning the insert to complete the circuit, rather than moving the blade. This minimises ruffling of the membrane and serration of the membrane edge. The membrane is then placed onto a coverslip for mounting, apical side up. Place one drop of Prolong ${ }^{\circledR}$ Gold Antifade reagent with 4', 6-diamidino-2-phenylindole (DAPI) (P36941, Thermo Fisher Scientific, Waltham, MA) or Vectashield Hardset mounting medium with phalloidin (TRITC) (H-1600, Vector Laboratories, Burlingame, CA, US) onto the centre of the 
membrane. Overlay the sample with a second clean coverslip, taking care not to introduce bubbles. Imaging may be performed after curing, using a confocal microscope. Primary antibodies are detailed in Table 4.

Note: The Transwell insert membrane does auto-fluoresce in the near UV excitation spectrum, therefore may exert interference with DAPI staining, in the form of strong background signal. If this occurs, another nuclear stain should be used if required.

Step 8: Fixation, embedding and haematoxylin \& eosin $(\boldsymbol{H} \& \boldsymbol{E})$ staining (Day 14 onwards). Inserts need to be carefully treated due to the delicate nature of bilayers. For this reason, all fixation, embedding and staining procedures are performed manually. Fix the inserts by immersion under $1 \mathrm{~mL} 10 \%$ Formalin, divided between the apical and basolateral compartments. Avoid fixing for greater than 24 hours since tissue antigens may either be masked or destroyed. Thirty minutes is adequate for insert membranes. Because paraffin is immiscible with water, tissue must be dehydrated at room temperature, before adding molten paraffin wax. To do this, immerse in $70 \%$ ethanol for 10 minutes, in $90 \%$ ethanol for 10 minutes, in $100 \%$ ethanol for 10 minutes and finally in isopropyl alcohol (IPA) $100 \%$ for 5 minutes.

Technical tip: Using IPA instead of xylene allows the steps to be performed with the insert in situ, which makes handling and orientation easier.

Place the whole insert into IPA/paraffin 1:1 for up to 1 hour at $58^{\circ} \mathrm{C}$. We perform this step at the embedding station, using prewarmed IPA and pre-mixing IPA with paraffin in a vessel large enough to accommodate one insert, but small enough to sit in the molten wax compartment. After 1 hour, embed the tissue in paraffin at $58^{\circ} \mathrm{C}$ for another hour. At this stage, the membrane should be removed from the insert with a fresh scalpel, taking care to keep the insert apical side up in order to minimise damage to cells. Removed membranes are then embedded in fresh paraffin in a mould deep enough to accommodate them, with the thin edge perpendicular to the edge of the microtome blade. The block is allowed to cool at the embedding station, then stored at room temperature or $2-8^{\circ} \mathrm{C}$ until sectioning.

For best results, perform sectioning after blocks have been on ice (fill a suitable container with water and freeze at $-20^{\circ} \mathrm{C}$ to form a solid block of ice) for 30 minutes. Cut 4-8 $\mu$ m thick sections using a rotary microtome and float the sections onto a pre-heated $56^{\circ} \mathrm{C}$ water bath. Collect sections on histological slides (Superfrost $+/+$ ) and dry the slides overnight at $37^{\circ} \mathrm{C}$. Slides can then be stored, either at room temperature or at $2-8^{\circ} \mathrm{C}$. for several years in slide storage boxes.

Haemotoxylin and Eosin $(\boldsymbol{H} \& \boldsymbol{E})$ Staining. The staining procedure is outlined in detail in Lee et al. ${ }^{30}$, therefore this section details technical tips only.
Technical tip 1: All dewaxing and staining steps are carried out manually in a fume hood, since cells in a bilayer are prone to detaching during staining/wash procedures in automated systems.

Technical tip 2: Sections cut from embedded membranes are best cut at a minimum of $4 \mu \mathrm{m}$. We have also successfully stained $8 \mu \mathrm{m}$ sections, which are less susceptible to detachment from the slide; however, this does affect clarity of images.

Technical tip 3: Rinsing slides under running tap water is best performed by filling a sandwich tub or similar with tap water and lowering a hose from the tap into the water, with the tap turned on to a trickle. Once confident that the water pressure is as low as possible, the user can then lower the cradle with slides into the tub. If this is still too aggressive and sections are detaching from the membrane or slide, we have successfully substituted running water for repeated rinsing in static tap water. To perform the rinsing step in this way, simply fill the tub with tap water and lower the cradle into the water without the hose. Leave for 5 minutes and gently lift the cradle out. Empty the tub and repeat the process until no stain is visible in the water (normally three to four washes).

\section{Results}

Immortalisation of ATII

We have isolated ATII cells as outlined in Lee et al..$^{30}$ (Figure 1) and immortalised them using two gene combinations through lentiviral transduction. The use of the stem cell regulator and proto-oncogene Bmil in conjunction with hTERT was used by Fulcher et al. to generate a novel human bronchial epithelial cell line $^{33}$ with considerable success. Like Fulcher et al., we found that the Bmi1/hTERT transduced B2AE cell line maintained genomic stability for up to at least 22 passages (Figure 2A). In addition, the proliferation rate was almost identical to that of the wild-type ATII cell (Figure 2B). Conversely, the SV40/hTERT transduced BATII cell line shows signs of genomic instability (Figure 2A) characteristic of viral oncogene derived cell lines ${ }^{34,35}$ at later passages, with a corresponding increase in proliferation rate by passage 10 (Figure 2B).

We analysed monolayers of each cell line alongside the wild-type ATII, as cultures seeded onto Lab-Tek II coverglass. The phosphate transporter SLC34A2 is expressed exclusively in the ATII cell in lung tissue and is therefore considered a marker for ATII cells ${ }^{36-38}$. Both BATII and B2AE cells formed colonies (Figure 3A); however, the BATII cells in particular formed three-dimensional structures (Figure 3B, middle row). These were flatter on the periphery and raised in the centre. The outside edge of the BATII colonies exhibited a flattened morphology. This corresponded to a strong signal for the mesenchymal marker vimentin, the expression of which has been previously reported as being instrumental to the role of ATII progenitor cells in wound healing ${ }^{39}$ and indicative of the upregulation of mesenchymal markers in ATII cells cultured under two-dimensional conditons $^{40}$. Whilst the ATII marker SLC34A2 was notably absent from the cells on the outside edge, it was very much 
A

\begin{tabular}{|c|c|c|c|}
\hline $\begin{array}{l}\text { Cell } \\
\text { Line }\end{array}$ & Passage & $\begin{array}{l}\text { Karyotype } \\
\text { (2n) }\end{array}$ & Counts \\
\hline \multirow{2}{*}{$\overline{\bar{E}}$} & 2 & 60 & 10 \\
\hline & 8 & 60 & 15 \\
\hline \multirow{5}{*}{ 言 } & 4 & 60 & 15 \\
\hline & 14 & 60 & 4 \\
\hline & & 64 & 1 \\
\hline & 23 & 60 & 6 \\
\hline & & 64 & 5 \\
\hline \multirow{3}{*}{ 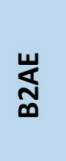 } & 7 & 60 & 10 \\
\hline & 12 & 60 & 10 \\
\hline & 22 & 60 & 10 \\
\hline
\end{tabular}

B

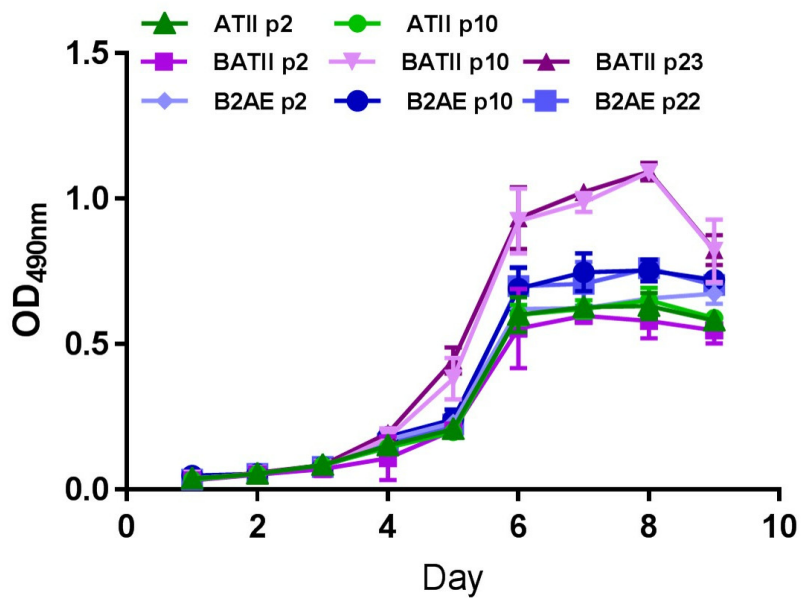

Figure 2. Characterisation of cell lines using karyotype and growth curve analysis. For karyotype analysis, a metaphase spread was performed on Colcemid cell cycle arrested cultures for both BATII and B2AE, comparing with the wild-type ATII (A). The Bmi1/hTERT transduced B2AE cell line was found to maintain the wild type bovine karyotype of $2 n=60$, whilst the SV40/hTERT transduced BATII cell line showed signs of genomic instability at both passages 14 and 23. This was reflected in a growth curve analysis of the two cell lines, which was performed by seeding primary ATII cells into a 96 well plate, comparing over 9 days with the BATII and B2AE cell lines (B), using the Cell Titre Aqueous One Assay (Promega). Later passages (p10 and p23) of BATII cells exhibited a considerably higher rate of proliferation than the wild type ATII, whilst the B2AE cell line at all passages was comparable with its wild type counterpart. Data shown as optical density read at $490 \mathrm{~nm}\left(\mathrm{OD}_{490 \mathrm{~nm}}\right)$; Mean $\pm \mathrm{SD}, \mathrm{n}=3$.

A

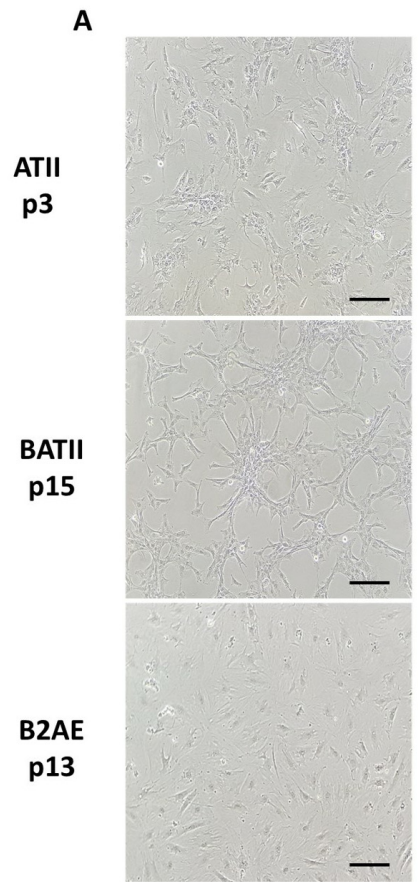

B

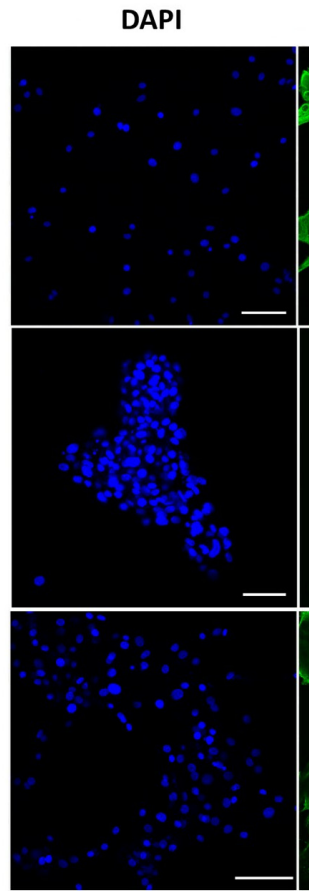

Vimentin

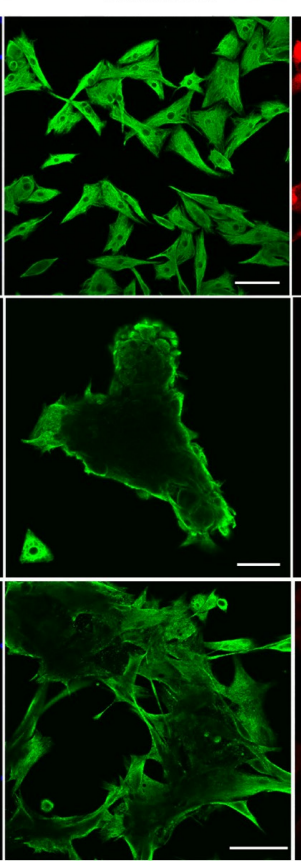

SLC34A2
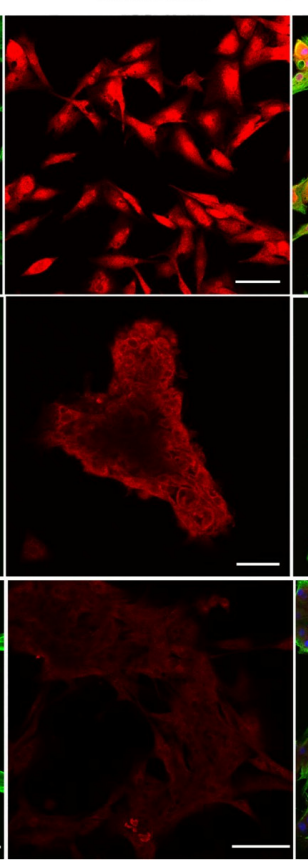

MERGE

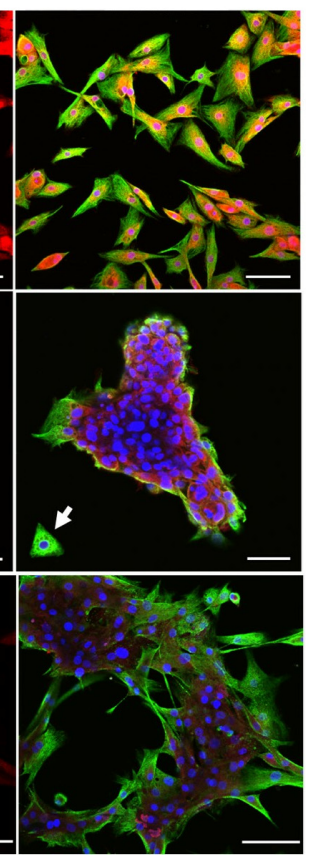

Figure 3. Characterisation of BATII and B2AE cell lines using light microscopy and confocal imaging of alveolar type II cell markers. Light microscopy images of the wild type ATII, SV40/hTERT lentivirus transduced BATII and Bmi1/hTERT lentivirus transduced B2AE were generated from cultures seeded into T75 $\mathrm{cm}^{2}$ flasks and imaged on a Nikon Eclipse Ci upright microscope (A). Scale bar $50 \mu \mathrm{m}$. For IF, each cell type was seeded onto a Nunc Lab Tek II coverglass, before fixation and staining with the ATII marker SLC434A2 and vimentin, a marker of epithelial-mesenchymal transition (B). Both cell lines were more prone to colony formation than their wild-type counterpart, with BATII cells in particular forming 3D structures, whilst B2AE frequently formed ring-like colonies around a central 'lumen'. Cells which exhibited a flattened morphology on the exterior of the colonies of both cell lines stained most strongly for vimentin, with one lone cell in the BATII image notable for the complete absence of SLC34A2 (middle panel, white arrow), which remained strong in the centre of the 3D colony. Scale bar $=100 \mu$ m. 
evident in the adjacent cells of the colony, which formed the inner margins.

The concomitant increase of vimentin expression and decrease in SLC34A2 expression was most notable in the isolated colony of the BATII culture (Figure 3B, middle row, white arrow). This can be seen in more detail in the movie, presented in Dataset 1, see Extended data ${ }^{41}$. The B2AE colonies were flatter in nature (Figure 3B, bottom row) and thus more mesenchymal in terms of protein expression, with visibly reduced SLC34A2 expression throughout with vimentin expression that was comparable to the wild type ATII cultures. This observation, reflective of the flatter nature of the colonies in these cultures, indicates that the B2AE cell line differentiates readily to ATI, taking on the mesenchymal phenotype.

\section{Matrigel cultures}

Previous literature has explored the role of extracellular matrix in the culture of epithelial cells of the distal airways $\mathrm{s}^{40,42}$. We therefore explored the use of Matrigel in our early BATII cultures, coating 2D plastic and Transwell inserts with a $10 \%$ solution of Matrigel in growth medium. Whilst cells seeded onto plastic (24 well format) formed the colonies thus far characteristic for this novel cell line (Figure 4A), the same cells, when seeded onto plastic coated with a $10 \%$ solution of Matrigel, formed a sheet of epithelial cells (Figure 4B-C), which eventually peeled away from the sides of the well. These sheets contained 3D structures, a feature even more prominent when the cells were seeded onto $12 \mathrm{~mm}$ diameter $3 \mu \mathrm{m}$ pore size Transwells (Figure 4D-H). The spheroidal, cyst-like structures seen in Figure 4D appeared to contain debris in the 'lumen' (Figure 4E). The structure was found to strongly express the ATII marker SLC34A2 around the periphery, whilst expression was notably absent in the 'lumen' (Figure 4F). When allowed to develop further ( $>7$ days), the sheet peeled back from the periphery of the Transwell insert membrane and formed a larger organoid structure visible with the naked eye (Figure 4G). This was embedded and sectioned for $H \& E$ staining and found to contain a live periphery (Figure 4H, black arrows) and a necrotic core (Figure 4H, 'N'). Whilst these cultures exhibited an ATII phenotype, they were not suitable for transport experiments, since they could not be cultured at air-liquid interface as a result of the peeling away from the Transwell edge. Extracellular matrix (ECM) is not necessary for the culture of bilayers, since endothelial cells produce a laminin-rich ECM in culture ${ }^{43}$.

\section{Bilayer characterisation (immunofluorescence)}

Bilayers were seeded for both novel ATII derived epithelial cell lines for comparison and cultured for 14 days, before probing for the ATII surface marker CD74 and mounting in TRITClabelled phalloidin to highlight cell morphology and bilayer thickness by F-actin visualisation. The apical aspect of the BATII bilayer (Figure 5A) revealed 3D structures, containing cells which strongly expressed CD74 (white arrows), whilst the surrounding flatter areas only stained positive for phalloidin. The basolateral aspect (Figure 5B) also stained strongly for
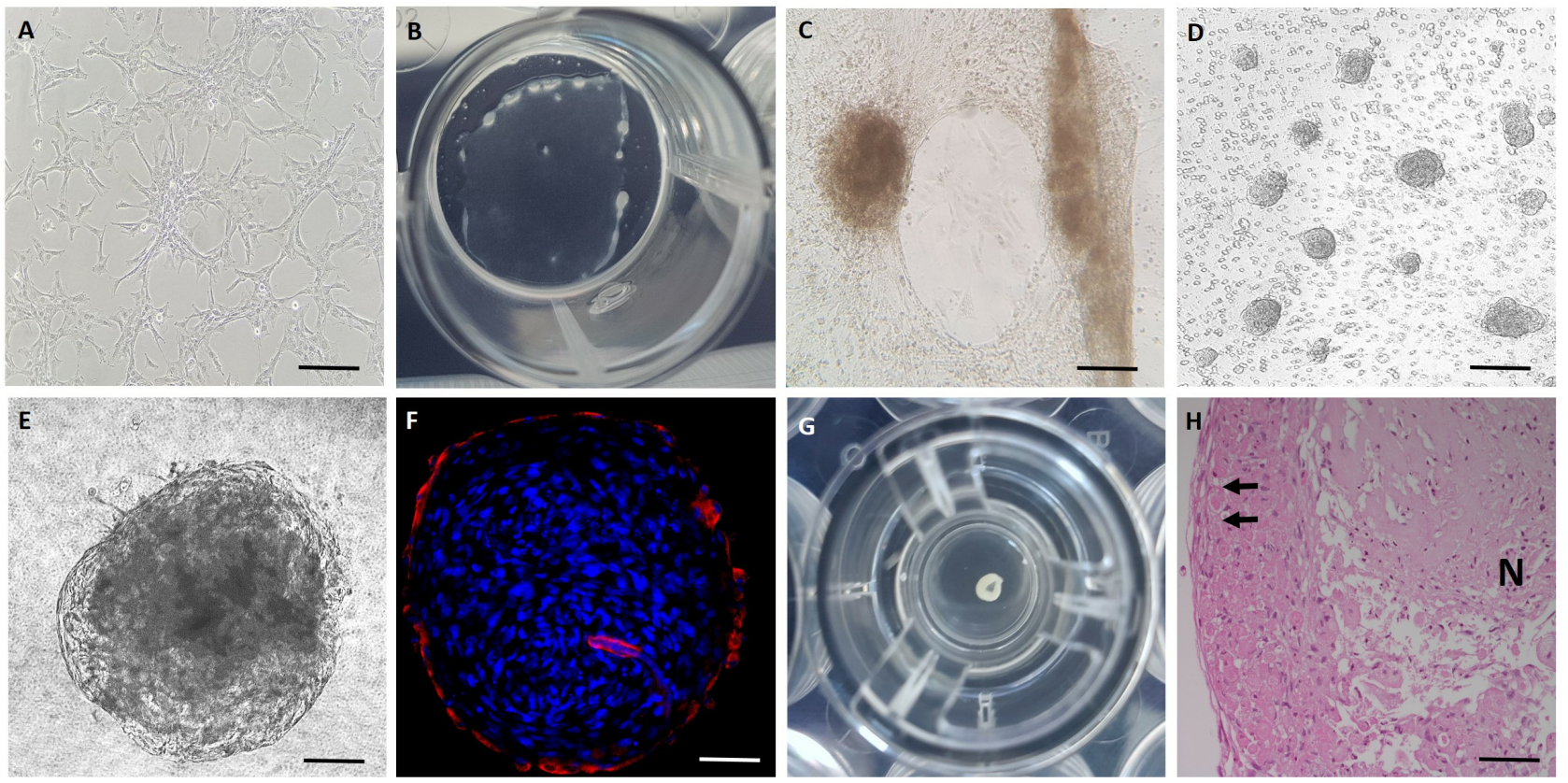

Figure 4. Comparison of culture surfaces and their effects on BATIl phenotype. BATII cells (p11) were grown on uncoated 2D plastic (A), 2D plastic coated in $10 \%$ Matrigel (B-C) and a $12 \mathrm{~mm}$ diameter Transwell insert (D-H). When cultured on uncoated plastic, BATIl cells formed colonies (A). On $10 \%$ Matrigel coated plastic, the cells formed sheets (B), containing 3D spheroid structures (C). When cultured on Transwell inserts, these spheroids developed into organoid like structures (D-E). Immunofluorescence probing for the ATII marker SLC34A2 revealed that the organoid like structure was strong for this ATII marker at the periphery, whilst the 'lumen' was devoid of any expression (F). Embedded and sectioned organoids $(\mathbf{G})$ were stained with haematoxylin and eosin $(\mathbf{H})$, which revealed a central, necrotic area, N, with live cells at the periphery (arrows). Scale bars are $50 \mu \mathrm{m}(\mathbf{A}), 50 \mu \mathrm{m}(\mathbf{C}), 100 \mu \mathrm{m}(\mathbf{D}), 25 \mu \mathrm{m}(\mathbf{E}-\mathbf{F})$ and $50 \mu \mathrm{m}(\mathbf{H})$. The insert pictured in $(\mathbf{C})$ is $12 \mathrm{~mm}$ diameter, with the organoid estimated at $3 \mathrm{~mm}$ diameter. 

F-actin and demonstrated the difference in morphology between the ATII derived BATII cells and the endothelial BPAECs. These can be observed in more detail in Dataset 2, see Extended dat $^{41}$. Similar differences were observed in the phalloidin staining between the B2AE apical (Figure 5C) and basolateral (Figure 5D) aspects. The B2AE cell line did not appear to form 3D structures and CD74 expression appeared to be absent in these bilayers. Whilst B2AE appear to lose the ability to express CD74 when cultured at ALI, they do retain the ability to express the ATII marker surfactant protein C (Figure 5E). The endothelial surface marker CD31 was used to distinguish the BPAEC endothelial layer from the B2AE epithelial layer (Figure 5F); however, the poor signal and flattened morphology rendered it difficult to distinguish this cell line from the epithelial layer using endothelial specific markers.

\section{Bilayer morphology}

We used haematoxylin and eosin (H\&E) staining to study the morphology of the bilayers in $4 \mu \mathrm{m}$ cross-sections taken from paraffin embedded Transwell inserts (Figure 6). Images clearly demonstrate the presence of two distinguishable layers on the apical and basolateral aspects of the membrane in both BATII (Figure 6A) and B2AE (Figure 6B) bilayers; however, detachment from the membrane during $H \& E$ processing was an issue and consequently, high-resolution images could not be obtained due to the distance between detached layers and the membrane. A repeat of the staining on sections acquired from bilayers seeded onto Transwell $12 \mathrm{~mm}$ diameter inserts with $0.4 \mu \mathrm{m}$ pores enabled the visualisation of the cuboidal BATII cells (Figure 6C) as a distinct layer from the underlying endothelial BPAECs, whilst the B2AE exhibited a more flattened morphology (Figure 6D), characteristic of the ATII descendants, the alveolar type I (ATI).

Using light microscopy, it was possible to visualise the pseudostratified morphology developed by the BATII epithelial layer when cultured as part of a bilayer (Figure 6E). This was in contrast to the underlying BPAEC, which formed a flattened monolayer (Figure 6F).

\section{Bilayer integrity}

Using the naked eye, it was possible to visualise the presence of any medium which had seeped through from the basolateral chamber to the apical side of the membrane. The BATII-containing bilayers were at air-liquid interface (ALI) from around 7 days, with less than $20 \mu \mathrm{L}$ medium present in the apical chamber on feeding days. Further evidence of integral tight junction formation was generated in the significant reduction of dextran blue 2000 (DB2000) permeability across bilayers seeded onto $6.5 \mathrm{~mm}$ diameter Transwell inserts (Figure 7A and Dataset 3,
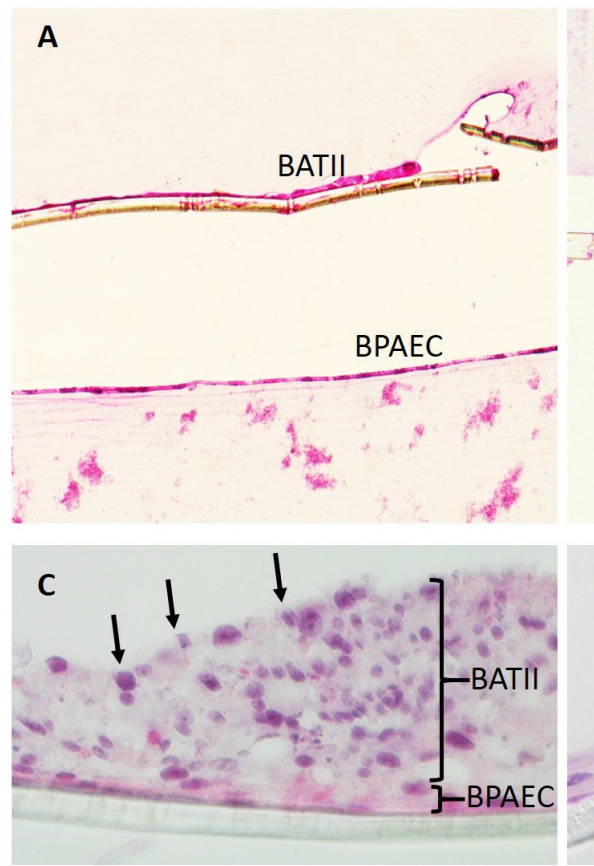

B

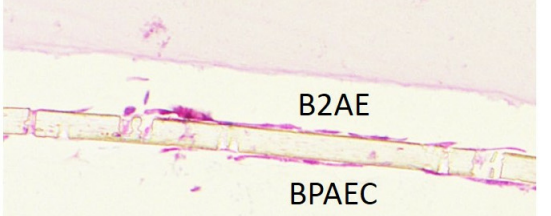

D

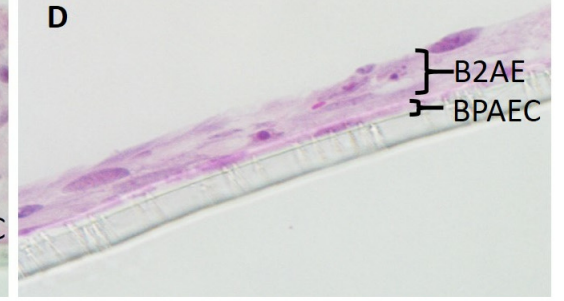

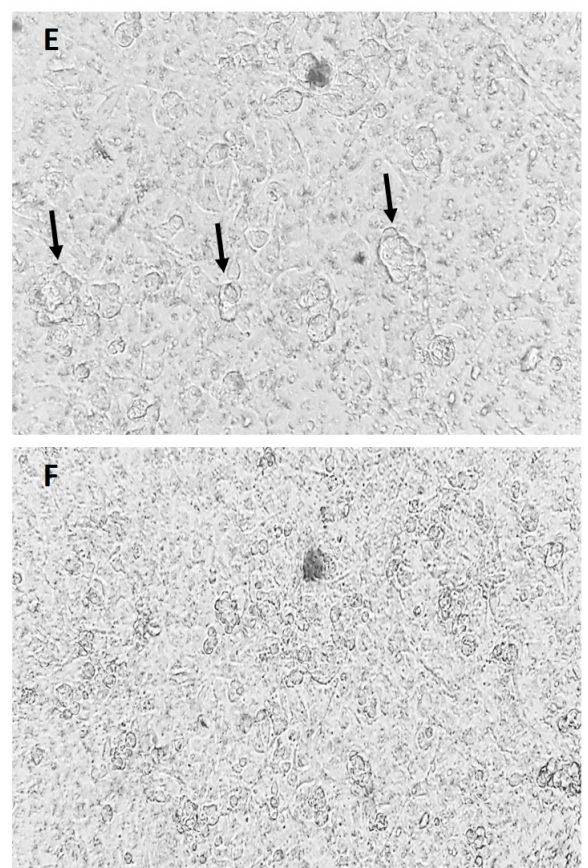

Figure 6. Characterisation of bilayers using histological analysis (haemotoxylin and eosin) and light microscopy. Bilayers containing both cell lines were also stained for morphological analysis using haematoxylin and eosin. An apical and basolateral layer is clearly observed in both the BATII (A) and B2AE (B) bilayers (magnification $10 \mathrm{x}$ ). The fragility of the membrane during processing meant that it was difficult to visualise the intact bilayer and so a bilayer was seeded onto a Transwell $12 \mathrm{~mm}$ diameter insert with $0.4 \mu \mathrm{m}$ pore size. This reduced the likelihood of cell detachment, as the endothelial cells remained on the apical aspect of the membrane, resulting in images where the epithelial BATII (C) and B2AE (D) layers are distinguishable from the underlying BPAEC, in which the staining is less intense (magnification $60 \mathrm{x}$ ). Cuboidal cells are visible particularly on the apical surface of the BATIl bilayer (C, arrows), whilst the B2AE appear to be flatter and more reminiscent of the squamous alveolar type I (ATI) cells. Visualisation by light microscopy of the BATII/BPAEC bilayer shows the formation of the pseudostratified BATII epithelial layer on the apical surface (E); examples of raised areas denoted by arrows, in contrast to the underlying endothelial BPAEC monolayer (F) (magnification $20 \mathrm{x}$ ). 
A

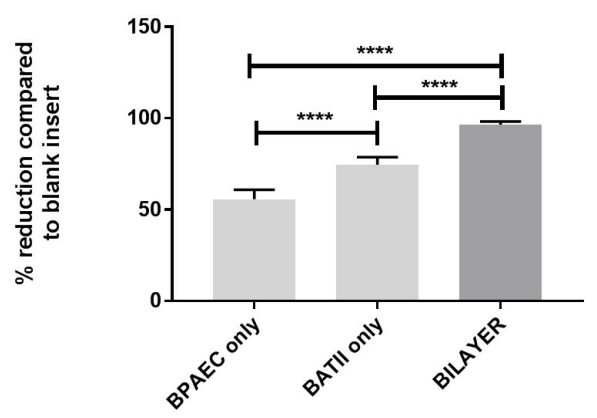

B

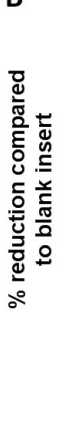

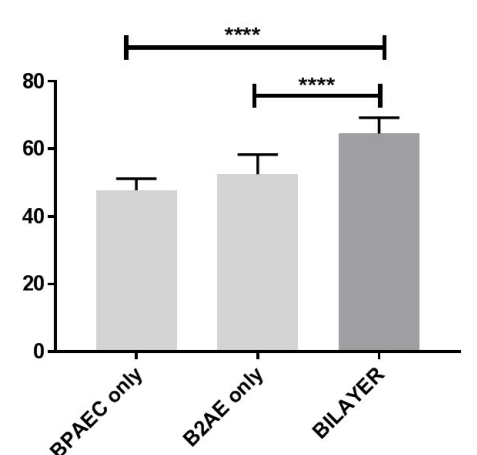

C

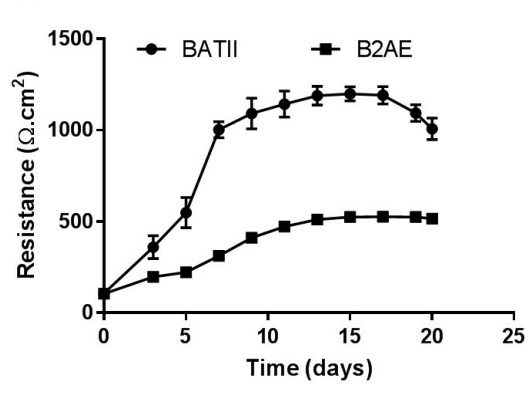

Figure 7. Dextran blue permeability and trans-epithelial electrical resistance (TEER) as a measure of bilayer integrity. The integrity of bilayers containing BATII (A) and B2AE (B) epithelial cells overlaid onto BPAEC endothelial cells were measured by dextran blue 2000 (DB2000) permeability, following 14 days culture at air-liquid interface (ALI) on $6.5 \mathrm{~mm}$ diameter, $8 \mu \mathrm{m}$ pore size Transwell membranes. Bilayers incorporating BATII cells as the epithelial layer significantly reduced apical to basolateral transport of DB2000 by almost $100 \%$ (ANOVA, with Tukey's Multiple Comparisons test; ${ }^{* * * *} \mathrm{P} \leq 0.0001$ ), whilst B2AE bilayers reduced permeability by $65 \%$ (*** $\mathrm{P} \leq 0.0001$ ). Whilst this was significant compared with inserts seeded with BPAEC cells only, this was a comparatively lower effect. Data shown is combined from three experiments (Mean $\pm S D ; n=9$ inserts per group) performed on different days. The increased permeability of DB2000 through B2AE bilayers was reflected in the trans-epithelial electrical resistance (TEER) (C). Readings were significantly lower for B2AE bilayers from day 3 (unpaired t-test, $\mathrm{P} \leq 0.0001$ ). Combined data shown from three experiments performed on different days, displayed as Mean $\pm \mathrm{SD}$; $n=18$ (inserts per group).

see Underlying data ${ }^{41}$ ); this was an average (mean) of $96 \%$ for the BATII derived bilayer (assigning blank insert as $0 \%$ reduction), compared to $75 \%$ reduction imparted by the BATII only monolayer (Tukey's multiple comparisons test; $\mathrm{P} \leq 0.0001$ ) and $56 \%$ for the endothelial BPAECs $(\mathrm{P} \leq 0.0001)$. This was in stark contrast to the $\mathrm{B} 2 \mathrm{AE}$ derived bilayer, which reduced DB2000 permeability by $65 \%$, compared to a $53 \%$ reduction by the B2AE only monolayer (Figure $7 \mathrm{~B})(\mathrm{P} \leq 0.0001)$. There was no significant difference between the B2AE and BPAEC monolayers, the latter of which reduced DB2000 permeability by $48 \%$. This suggests B2AE cells formed a less integrated layer than BATII cells, supported by the considerably lower TEER values of B2AE derived bilayers, when compared to BATII derived bilayers, obtained over 21 days after seeding the epithelial layer (Figure 7C and Dataset 4, see Underlying data ${ }^{41}$ ). This finding was significant (unpaired t-test; $\mathrm{P} \leq 0.0001$ ).

\section{Discussion}

We describe here a method by which researchers may construct a bilayer for medium term culture, consisting of an immortalised alveolar type II (using the BATII novel cell line) epithelial cell layer overlaid onto a bovine pulmonary arterial endothelial cell (BPAEC) layer. Together, these two cell types recapitulate the highly gas permeable bilayer observed in vivo in the bovine alveolus. This is the first bovine bilayer model of the alveolus presented in the literature to our knowledge and thus has vast implications for the progression of research into bovine respiratory diseases, zoonoses and host pathogen interactions of the distal airways.

In order to reduce inter-experimental variability and therefore provide consistent data that are comparable with other studies, we opted to immortalise the ATII cells isolated according to our previously published protocol ${ }^{30}$. Conventionally, immortalisation involves the introduction of viral oncogenes, for example those encoding the E6 and E7 proteins of human papilloma virus (HPVE6/E7) and the large tumour (T) antigen derived from Simian virus (SV40). These, however, result in the trade off of genomic instability with the increased proliferation rate, which arises through the loss of the p53 checkpoint $^{44}$, amongst other notable gene expression anomalies and an aberrant karyotype $\mathrm{k}^{34,35,45}$. For this reason, we chose to generate an additional cell line, combining the proto-oncogene and stem cell regulator $\mathrm{B}$ cell-specific Moloney murine leukemia virus integration site 1 , Bmil with the catalytic subunit of human telomerase, hTERT, to enable comparison with an SV40/hTERT immortalised cell line. The introduction of hTERT alone extends proliferative capacity; however, it does not fully immortalise cells ${ }^{46,47}$. Conversely, the combination of hTERT with Bmil has been previously reported to result in a genetically stable human bronchial epithelial cell (HBEC) line ${ }^{33}$, with the ability to form a differentiated, pseudostratified epithelium when grown at air-liquid interface (ALI), with a similar proliferation rate to nonimmortalised cells. More recently, this combination was also used to successfully generate a human alveolar type II cell line ${ }^{48}$. Other alternatives to viral oncogenes include cyclin-dependant kinase $4(C d k 4)$, as used by Ramirez et $a l .{ }^{46}$. In their characterisation of HBECs immortalised using the combination of hTERT and $C d k 4$, Ramirez et al. do report regions of duplication (chromosomes 5 and 20). The gene expression profile, however, closely aligns with the wild-type and therefore this combination may yield another useful cell line derived from ATII cells.

In our studies, the combination of Bmil and hTERT in the generation of the $\mathrm{B} 2 \mathrm{AE}$ cell line by lentiviral transduction did 
indeed yield a proliferation rate comparable to ATII cells and a stable karyotype. However, our intentions to use the cells in a medium-throughput assay to study host-pathogen interactions were hampered by the slow growth. This, together with the readiness of the $\mathrm{B} 2 \mathrm{AE}$ to develop a squamous morphology indicative of differentiated alveolar type I (ATI) cells on plastic and when cultured as part of a bilayer made this cell line less suitable for studies of the role of ATII cells in innate immunity under ALI growth conditions.

Continuous epithelial cell lines are often reduced in their differentiation capacity (for example the BEAS-2B line ${ }^{49}$ ), sometimes do not form the polarised layers characteristic of epithelial cells (for example the $16 \mathrm{HBE} 14^{0-} \operatorname{line}^{50}$ ) or demonstrate a reduced ability to form tight junctions (for example the A549 line $)^{51}$. It was therefore important to characterise both the BATII and B2AE cell lines for these traits. The B2AE cell line showed a reduced propensity to develop tight junctions, as indicated by the formation of a relatively inefficient barrier to DB2000 when compared to the BATII cell line and relatively low TEER measurements over 21 days, when cultured as the epithelial component of a bilayer on Transwell inserts (Figure 7C and Dataset 4, see Underlying data ${ }^{41}$ ). A recently reported human alveolar epithelial cell line generated by the introduction of Bmil and hTERT ${ }^{48}$ reported TEER values of up to 400 $\Omega . \mathrm{cm}^{2}$. Our own findings were that the B2AE cell line generated a maximum TEER of circa $500 \Omega . \mathrm{cm}^{2}$ by day 10 of culture as part of a bilayer. This was insufficient to maintain ALI beyond a couple of hours; therefore, the majority of culture time of B2AE bilayers was as a submerged culture. By contrast, the BATII cell line reached values in excess of $1200 \Omega . \mathrm{cm}^{2}$. These were comparable with rat primary alveolar epithelial cells and considerably higher than the human ATI-like A549 line f $^{52}$. BPAEC cells alone did not generate TEER values of greater than $200 \Omega . \mathrm{cm}^{2}$, suggesting they contribute relatively little to the impermeability of the bilayer.

It is possible that in our studies, the repression of p53 by the large $\mathrm{T}$ antigen of $\mathrm{SV}_{40} 0^{44}$ has had a serendipitous beneficial effect. Certainly, when cultured at ALI in the presence or absence of BPAECs, the BATII cell line retains the ATII markers CD74 and SLC34A2 to a much greater degree than the B2AE cell line. Previous studies have reported that CD74 is lost quickly in the culture of primary ATII cells as they differentiate into $\mathrm{ATI}^{2,53}$. The BATII cell line appeared to retain expression of CD74 after two weeks culture at ALI, along with a pseudostratified morphology. It has been proposed that CD74 is a marker of proliferative capacity in ATII cells and that expression of this surface marker enables interaction of ATII cells with the macrophage migration inhibitory factor (MIF), stimulating ATII proliferation and alveolar repair in response to the loss of ATI cells ${ }^{2}$. Our findings support these data, since the B2AE cell line in our bilayer loses CD74 expression and takes on a squamous appearance, simultaneously failing to form a sufficiently integrated layer to allow culture at ALI. Taking these comparisons into account, we plan to focus our efforts on the BATII cell line for our own studies, which rely on a maintenance of the ATII phenotype by a sub-population of the cells when cultured as part of a bilayer. We do, however, propose that other researchers may find the B2AE cell line useful, such as in studies where a native karyotype is crucial.

The ability of the BATII cell line to maintain proliferative capacity and the expression of ATII markers, such as CD74 and SLC34A2, in 3D structures such as those observed in our Matrigel cultures alludes to their potential in spheroid and organoid studies of the alveolar epithelium. These spheroids were reminiscent of those reported by Lee et al. ${ }^{52}$. As such, they may be of interest to researchers in the field of developmental biology, for example in exploring the mechanisms of alveolar differentiation via the Wnt pathway, building on previous organoid culture approaches ${ }^{54}$. Previous literature reports the generation of organoids predominantly from sacrificed animals, as reviewed by Barkauskas et al. ${ }^{55}$. Disadvantages of this approach include the cost and logistics of animal housing (a particularly significant hurdle when studying larger animals such as bovines), the ethical considerations of such methods due to the invasive nature of procedures used to simulate disease status and the reported necessity for mesenchymal 'support' cells for the formation of ATII-derived organoids in 3D culture ${ }^{56}$. The BATII cell line derived spheroids require further characterisation, but we suggest that they offer much potential in the discipline of 3D organoid studies of the distal lung. Since our ongoing studies require the culture of cells at ALI as part of a bilayer, we have ceased to use Matrigel in our bilayer cultures, since the formation of organoids in this system causes the epithelial layer to peel back from the edges of the insert, causing 'leakiness' of the model.

The formation of an integral bilayer with BPAECs lends the BATII cell line to pharmacological studies ${ }^{57}$, or migration studies, including, but not exclusive to, neutrophils ${ }^{58}$. No such studies have been performed in a bovine bilayer thus far; therefore, we anticipate that the bilayer outlined here will facilitate bovine studies that parallel studies published previously for human in vitro models. The model enables users to obtain representative alveolar bilayers with desirable physiological and structural features of the native bovine alveolus within three weeks, whilst overcoming the challenges of housing large animals or the absence of large animal facilities. Most pertinent to the ethos of the 3Rs (in particular Replace), our bilayer model, ready to use in as little as three weeks, may be used as an in vitro alternative to in vivo experiments studying bovine respiratory diseases, for which 95 live cattle were used in the UK alone in $2016^{29}$. These include, but are not exclusive to, bovine tuberculosis, bovine respiratory disease and bovine syncytial virus. Our method could also be used in parallel with live animal studies. For comparison with an in vivo scenario, one recent study in which cattle were infected with live M.tuberculosis was conducted using 12 calves reared from birth to six months of age in bio-containment level 3 laboratory facilities. Cattle were culled ten weeks post infection ${ }^{59}$, resulting in an overall study period of almost nine months. Whilst the number of live animals used may not be considered to be high, the authors would emphasise that the protracted nature of such experiments is a considerable drawback. It may also be argued that 
cattle used in such studies are not granted three of the "five freedoms of animal welfare'. These are "freedom from pain, injury or disease", "freedom to express normal behaviour" and "freedom from fear and distress" 25 .

Of particular interest to our group is the application of the model to study host-pathogen interactions in the bovine alveolus, between the ATII cell and M. bovis. Live animal studies have thus far provided a wealth of information, particularly those involving the natural target of $M$. bovis, the cattle themselves, as reviewed by Gregson et al. ${ }^{57}$. The close relationship between $M$. bovis and $M$. tuberculosis implies that an in vitro bovine bilayer model would be of use in elucidating data for both pathogens and therefore enable comparative studies in disease pathogenesis. This has certainly been demonstrated by the evaluation of human treatments and vaccines in the bovine live animal model ${ }^{22,23}$. In order to accelerate advances in therapies and control strategies, however, a more fundamental understanding of early disease pathogenesis is urgently required. Early events are difficult to study in live animal models, whereas the use of an in vitro bilayer could allow real time studies to be performed and would overcome the challenges of housing cattle in containment level 3 facilities.

To summarise, we present here two novel ATII derived cell lines, BATII and B2AE, together with a simple in vitro bilayer model of the bovine alveolus, including a detailed protocol by which other users can establish the model in their own institution. We have discussed the suitability of the immortalised BATII cells as organoid cultures to enable the translation of human developmental biology and tissue regeneration studies to the bovine model, whilst comparing and contrasting both cell lines generated by the lentiviral transduction of ATII cells with the viral oncogene SV40/hTERT combination (BATII), versus the protooncogene Bmil/hTERT combination (B2AE). We have summarised how the use of the BATII cell line, in conjunction with the endothelial cell line BPAEC within a functional bilayer, could act as a viable alternative to live animal studies, overcoming logistical challenges associated with large animal models of disease pathogenesis. This applies particularly to pathogens such as $M$. bovis and $M$. tuberculosis, which require containment level 3 facilities. We propose that the bilayer model will allow the study of early host-pathogen interactions between the alveolar epithelium and the invading (respiratory) agent, including in the context of additional components of the innate immune system, such as neutrophils and macrophages. Such studies are extremely difficult to conceive in the in vivo setting due to the transient nature of such events. All of the components of the model are available either commercially (BPAECs, see 'Culture conditions of BPAECs') or through collaboration with the authors (BATII and B2AE cell lines). As such, other researchers are encouraged to consider this model as an alternative to live animal models. In doing so, there is considerable potential to advance the fields of respiratory disease in cattle, align research of bovine and human zoonoses and closely related pathogens in terms of preventative strategies as well as novel treatments and disease interventions. Consequently, the bilayer model offers great potential in replacing live animals used in the research of respiratory diseases affecting the distal airways. The authors are willing to discuss collaborations with other researchers wishing to use the bovine alveolar type II cell lines.

\section{Data availability}

Underlying data

Open Science Framework: f1000 research. https://doi.org/ 10.17605/OSF.IO/CXMBU ${ }^{41}$

The project contains the following underlying data:

- Dataset 3_dextran blue assay.csv (Raw data underlying dextran blue permeability assay presented in Figure 7)

- Dataset 4_TEER.csv (Raw TEER values underlying Figure 7)

\section{Extended data}

Open Science Framework: f1000 research. https://doi.org/ 10.17605/OSF.IO/CXMBU ${ }^{41}$

The project contains the following extended data:

- Dataset 1_3D BATII.mp4(3D construction of the morphology of a BATII cell colony)

- Dataset 2_Z stack bilayer.mp4 (Z stack of a bilayer composed of an apical BATII epithelial layer overlaid onto BPAECs)

Data are available under the terms of the Creative Commons Zero "No rights reserved" data waiver (CC0 1.0 Public domain dedication).

\section{Grant information}

This study was supported by a strategic grant (NC/M002047/1), awarded by the National Centre for the Replacement, Refinement and Reduction of Animals in Research (NC3Rs).

The funders had no role in study design, data collection and analysis, decision to publish, or preparation of the manuscript.

\section{Acknowledgments}

The authors would like to thank members of the Veterinary Pathology Centre and Biochemical Sciences \& Bioimaging Core Facility at the University of Surrey for their assistance.
1. Vasilescu DM, Gao Z, Saha PK, et al.: Assessment of morphometry of pulmonary acini in mouse lungs by nondestructive imaging using multiscale microcomputed tomography. Proc Natl Acad Sci U S A. 2012; 109(42): 17105-10. PubMed Abstract | Publisher Full Text | Free Full Text

2. Marsh LM, Cakarova L, Kwapiszewska G, et al:: Surface expression of CD74 by type II alveolar epithelial cells: a potential mechanism for macrophage migration inhibitory factor-induced epithelial repair. Am J Physiol Lung Cell Mol Physiol. 2009; 296(3): L442-52.

PubMed Abstract | Publisher Full Text

3. Chen J, Chen Z, Narasaraju T, et al.: Isolation of highly pure alveolar epithelial 
type I and type II cells from rat lungs. Lab Invest. 2004; 84(6): 727-35. PubMed Abstract | Publisher Full Text

4. Chen Z, Jin N, Narasaraju T, et al.: Identification of two novel markers for alveolar epithelial type I and II cells. Biochem Biophys Res Commun. 2004; 319(3): 774-80.

PubMed Abstract | Publisher Full Text

5. Johnson MD, Widdicombe JH, Allen L, et al.: Alveolar epithelial type I cells contain transport proteins and transport sodium, supporting an active role for type I cells in regulation of lung liquid homeostasis. Proc Natl Acad Sci U S A. 2002; 99(4): 1966-71

PubMed Abstract | Publisher Full Text | Free Full Text

6. Kapanci Y, Weibel ER, Kaplan HP, et al:: Pathogenesis and reversibility of the pulmonary lesions of oxygen toxicity in monkeys. II. Ultrastructural and morphometric studies. Lab Invest. 1969; 20(1): 101-18. PubMed Abstract

7. Kaplan HP, Robinson FR, Kapanci Y, et al:: Pathogenesis and reversibility of the pulmonary lesions of oxygen toxicity in monkeys. I. Clinical and light microscopic studies. Lab Invest. 1969; 20(1): 94-100. PubMed Abstract

8. Evans MJ, Cabral LJ, Stephens RJ, et al:: Renewal of alveolar epithelium in the rat following exposure to $\mathrm{NO}_{2}$. Am J Pathol. 1973; 70(2): 175-98. PubMed Abstract | Free Full Text

9. Barkauskas CE, Cronce MJ, Rackley CR, et al:: Type 2 alveolar cells are stem cells in adult lung. J Clin Invest. 2013; 123(7): 3025-36. PubMed Abstract | Publisher Full Text | Free Full Text

10. Fuchs S, Hollins AJ, Laue M, et al.: Differentiation of human alveolar epithelial cells in primary culture: morphological characterization and synthesis of caveolin-1 and surfactant protein-C. Cell Tissue Res. 2003; 311(1): 31-45. PubMed Abstract | Publisher Full Text

11. Degryse AL, Lawson WE: Progress toward improving animal models for idiopathic pulmonary fibrosis. Am J Med Sci. 2011; 341(6): 444-9. PubMed Abstract | Publisher Full Text | Free Full Text

12. Mason RJ, Williams MC: Type II alveolar cell. Defender of the alveolus. Am Rev Respir Dis. 1977; 115(6 Pt 2): 81-91. PubMed Abstract

13. Whitsett JA, Alenghat $\mathrm{T}$ : Respiratory epithelial cells orchestrate pulmonary innate immunity. Nat Immunol. 2015; 16(1): 27-35. PubMed Abstract | Publisher Full Text | Free Full Text

14. Whitsett JA, Wert SE, Weaver TE: Diseases of pulmonary surfactant homeostasis. Annu Rev Pathol. 2015; 10: 371-93. PubMed Abstract | Publisher Full Text | Free Full Text

15. Nayak A, Dodagatta-Marri E, Tsolaki AG, et al.: An Insight into the Diverse Roles of Surfactant Proteins, SP-A and SP-D in Innate and Adaptive Immunity. Front Immunol. 2012; 3: 131.

PubMed Abstract | Publisher Full Text | Free Full Text

16. Crouch $\mathrm{E}, \mathrm{Tu} \mathrm{Y}$, Briner $\mathrm{D}$, et al.: Ligand specificity of human surfactant protein $D$ : expression of a mutant trimeric collectin that shows enhanced interactions with influenza A virus. J Biol Chem. 2005; 280(17): 17046-56.

PubMed Abstract | Publisher Full Text

17. Hartshorn KL, White MR, Tecle T, et al:: Innate defense against influenza A virus: activity of human neutrophil defensins and interactions of defensins with surfactant protein D. J Immunol. 2006; 176(11): 6962-72. PubMed Abstract | Publisher Full Text

18. Oberley RE, Ault KA, Neff TL, et al.: Surfactant proteins A and D enhance the phagocytosis of Chlamydia into THP-1 cells. Am J Physiol Lung Cell Mol Physiol. 2004; 287(2): L296-306.

PubMed Abstract | Publisher Full Text

19. Kishore U, Greenhough TJ, Waters P, et al:: Surfactant proteins SP-A and SP-D: structure, function and receptors. Mol Immunol. 2006; 43(9): 1293-315. PubMed Abstract | Publisher Full Text

20. Birkness KA, Deslauriers M, Bartlett JH, et al:: An in vitro tissue culture bilayer model to examine early events in Mycobacterium tuberculosis infection. Infect Immun. 1999; 67(2): 653-8.

PubMed Abstract | Free Full Text

21. Williams A, Orme IM: Animal Models of Tuberculosis: An Overview. Microbiol Spectr. 2016; 4(4). PubMed Abstract | Publisher Full Text

22. Dean GS, Rhodes SG, Coad M, et al:: Isoniazid treatment of Mycobacterium bovis in cattle as a model for human tuberculosis. Tuberculosis (Edinb). 2008 ; 88(6): 586-94.

PubMed Abstract | Publisher Full Text

23. Vordermeier HM, Villarreal-Ramos B, Cockle PJ, et al:: Viral booster vaccines improve Mycobacterium bovis BCG-induced protection against bovine tuberculosis. Infect Immun. 2009; 77(8): 3364-73. PubMed Abstract | Publisher Full Text | Free Full Text

24. Waters WR, Whelan AO, Lyashchenko KP, et al.: Immune responses in cattle inoculated with Mycobacterium bovis, Mycobacterium tuberculosis, or Mycobacterium kansasii. Clin Vaccine Immunol. 2010; 17(2): 247-52. PubMed Abstract | Publisher Full Text | Free Full Text

25. Webster J: Animal Welfare: Freedoms, Dominions and "A Life Worth Living". Animals (Basel). 2016; 6(6): pii: E35.

PubMed Abstract | Publisher Full Text | Free Full Text

26. Su F, Liu X, Liu G, et al.: Establishment and evaluation of a stable cattle type II alveolar epithelial cell line. PLoS One. 2013; 8(9): e76036.

PubMed Abstract | Publisher Full Text | Free Full Text

27. Lee DF, Chambers MA: Isolation of Alveolar Type II Cells from Adult Bovine Lung. Curr Protoc Toxicol. 2019; e71.

PubMed Abstract | Publisher Full Text

28. Urban-Chmiel R, Grooms DL: Prevention and control of bovine respiratory disease. J Livestock Sci. 2012; 3: 27-36.

Reference Source

29. Office H: Annual Statistics of Scientific Procedures on Living Animals Great Britain 2016.

Reference Source

30. Lee DF, Salguero FJ, Grainger D, et al:: Isolation and characterisation of alveolar type II pneumocytes from adult bovine lung. Sci Rep. 2018; 8(1): 11927.

PubMed Abstract | Publisher Full Text | Free Full Text

31. Ye J, Coulouris G, Zaretskaya I, et al:: Primer-BLAST: a tool to design targetspecific primers for polymerase chain reaction. BMC Bioinformatics. 2012; 13: 134. PubMed Abstract | Publisher Full Text | Free Full Text

32. Campos $\mathrm{PB}$, Sartore RC, Abdalla SN, et al.: Chromosomal spread preparation of human embryonic stem cells for karyotyping. J Vis Exp. 2009; (31): pii: 1512. PubMed Abstract | Publisher Full Text | Free Full Text

33. Fulcher ML, Gabriel SE, Olsen JC, et al:: Novel human bronchial epithelial cell lines for cystic fibrosis research. Am J Physiol Lung Cell Mol Physiol. 2009; 296(1): L82-91.

PubMed Abstract | Publisher Full Text | Free Full Text

34. Woods C, LeFeuvre C, Stewart N, et al:: Induction of genomic instability in SV40 transformed human cells: sufficiency of the $\mathrm{N}$-terminal 147 amino acids of large T antigen and role of pRB and p53. Oncogene. 1994; 9(10): 2943-50. PubMed Abstract

35. Hein J, Boichuk S, Wu J, et al:: Simian virus $\mathbf{4 0}$ large $\mathbf{T}$ antigen disrupts genome integrity and activates a DNA damage response via Bub1 binding. $J$ Virol. 2009; 83(1): 117-27.

PubMed Abstract | Publisher Full Text | Free Full Text

36. Yin BW, Kiyamova R, Chua R, et al.: Monoclonal antibody MX35 detects the membrane transporter NaPi2b (SLC34A2) in human carcinomas. Cancer Immun. 2008; 8: 3.

PubMed Abstract | Free Full Tex

37. Hashimoto M, Wang DY, Kamo T, et al:: Isolation and localization of type Ilb $\mathrm{Na} / \mathrm{Pi}$ cotransporter in the developing rat lung. Am J Pathol. 2000; 157(1): 21-7. PubMed Abstract | Publisher Full Text | Free Full Text

38. Traebert M, Hattenhauer O, Murer $\mathrm{H}$, et al:: Expression of type II Na-P cotransporter in alveolar type II cells. Am J Physiol. 1999; 277(5): L868-73. PubMed Abstract | Publisher Full Text

39. Fujino N, Kubo H, Suzuki T, et al:: Isolation of alveolar epithelial type II progenitor cells from adult human lungs. Lab Invest. 2011; 91(3): 363-78. PubMed Abstract | Publisher Full Text | Free Full Text

40. Calle EA, Mendez JJ, Ghaedi M, et al.: Fate of distal lung epithelium cultured in a decellularized lung extracellular matrix. Tissue Eng Part A. 2015; 21(11-12): 1916-28.

PubMed Abstract | Publisher Full Text | Free Full Text

41. Lee D, Chambers M: f1000research. 2019. http://www.doi.org/10.17605/OSF.IO/CXMBU

42. Bhowmick R, Gappa-Fahlenkamp H: Cells and Culture Systems Used to Model the Small Airway Epithelium. Lung. 2016; 194(3): 419-28.

PubMed Abstract | Publisher Full Text

43. Davis GE, Senger DR: Endothelial extracellular matrix: biosynthesis, remodeling, and functions during vascular morphogenesis and neovessel stabilization. Circ Res. 2005; 97(11): 1093-107.

PubMed Abstract | Publisher Full Text

44. Sheppard HM, Corneillie SI, Espiritu C, et al:: New insights into the mechanism of inhibition of p53 by simian virus 40 large T antigen. Mol Cell Biol. 1999; 19(4): 2746-53.

PubMed Abstract | Publisher Full Text | Free Full Text

45. Cudré-Mauroux C, Occhiodoro T, König S, et al:: Lentivector-mediated transfer of Bmi-1 and telomerase in muscle satellite cells yields a duchenne myoblast cell line with long-term genotypic and phenotypic stability. Hum Gene Ther. 2003; 14(16): 1525-33.

PubMed Abstract | Publisher Full Text

46. Ramirez RD, Sheridan S, Girard L, et al:: Immortalization of human bronchial epithelial cells in the absence of viral oncoproteins. Cancer Res. 2004; 64(24): 9027-34.

PubMed Abstract | Publisher Full Text

47. Houtmeyers E, Gosselink R, Gayan-Ramirez G, et al:: Effects of drugs on mucus clearance. Eur Respir J. 1999; 14(2): 452-67.

PubMed Abstract | Publisher Full Text

48. Tamo L, Hibaoui Y, Kallol S, et al.: Generation of an alveolar epithelial type II cell line from induced pluripotent stem cells. Am J Physiol Lung Cell Mol Physiol. 2018; 315(6): L921-L932.

PubMed Abstract | Publisher Full Text

49. Stewart CE, Torr EE, Mohd Jamili NH, et al:: Evaluation of differentiated human bronchial epithelial cell culture systems for asthma research. J Allergy (Cairo). 2012; 2012: 943982

PubMed Abstract | Publisher Full Text | Free Full Text 
Forbes B, Ehrhardt C: Human respiratory epithelial cell culture for drug delivery applications. Eur J Pharm Biopharm. 2005; 60(2): 193-205. PubMed Abstract | Publisher Full Text

51. Cooney DJ, Hickey AJ: Cellular response to the deposition of diesel exhaust particle aerosols onto human lung cells grown at the air-liquid interface by inertial impaction. Toxicol In Vitro. 2011; 25(8): 1953-65. PubMed Abstract | Publisher Full Text

52. Srinivasan $\mathrm{B}$, Kolli $\mathrm{AR}$, Esch $\mathrm{MB}$, et al: TEER measurement techniques for in vitro barrier model systems. J Lab Autom. 2015; 20(2): 107-26. PubMed Abstract | Publisher Full Text | Free Full Text

53. Lee JH, Kim J, Gludish D, et al:: Surfactant protein-C chromatin-bound green fluorescence protein reporter mice reveal heterogeneity of surfactant protein C-expressing lung cells. Am J Respir Cell Mol Biol. 2013; 48(3): 288-98. PubMed Abstract | Publisher Full Text | Free Full Text

54. Lee JH, Tammela T, Hofree M, et al:: Anatomically and Functionally Distinct Lung Mesenchymal Populations Marked by Lgr5 and Lgr6. Cell. 2017; 170(6): 1149-1163.e12.

PubMed Abstract | Publisher Full Text | Free Full Text organoids: current uses and future promise. Development. 2017; 144(6): 986-997.

PubMed Abstract | Publisher Full Text | Free Full Tex

56. McQualter JL, Yuen K, Williams B, et al.: Evidence of an epithelial stem/ progenitor cell hierarchy in the adult mouse lung. Proc Natl Acad Sci U S A. 2010; 107(4): 1414-9.

PubMed Abstract | Publisher Full Text | Free Full Text

57. Gregson L, Hope WW, Howard SJ: In vitro model of invasive pulmonary aspergillosis in the human alveolus. Methods Mol Biol. 2012; 845: 361-7. PubMed Abstract | Publisher Full Text

58. Weppler A, Rowter D, Hermanns I, et al:: Modulation of endotoxin-induced neutrophil transendothelial migration by alveolar epithelium in a defined bilayer model. Exp Lung Res. 2006; 32(10): 455-82.

PubMed Abstract | Publisher Full Text

59. Villarreal-Ramos B, Berg S, Whelan A, et al.: Experimental infection of cattle with Mycobacterium tuberculosis isolates shows the attenuation of the human tubercle bacillus for cattle. Sci Rep. 2018; 8(1): 894.

PubMed Abstract | Publisher Full Text | Free Full Text 


\section{Open Peer Review}

\section{Current Peer Review Status: ? ? ?}

\section{Version 1}

Reviewer Report 31 May 2019

https://doi.org/10.5256/f1000research.20472.r46561

(c) 2019 Davies R. This is an open access peer review report distributed under the terms of the Creative Commons Attribution License, which permits unrestricted use, distribution, and reproduction in any medium, provided the original work is properly cited.

\section{Robert L Davies \\ Institute of Infection, Immunity and Inflammation, College of Medical, Veterinary and Life Sciences, University of Glasgow, Glasgow, UK}

This paper describes the establishment of a co-culture bilayer model of the bovine alveolus using bovine pulmonary arterial endothelial cells (BPAECs) and immortalised bovine alveolar type II epithelial cells cultured for 14 days at an air-liquid interface (ALI). The authors highlight the practical, scientific and 3Rs benefits of their model and provide examples of current and potential applications.

The rationale for establishing a bilayer alveolus model is well justified and the methodology is generally detailed and clear. The authors have chosen to create their bilayer by seeding the alveolar epithelial cells directly on top of confluent BPAECS and culturing at ALI (it is not clear whether an initial submerged phase was used which is normal practice). However, in previously established bilayer models of the alveolus (Hope et al., 2007¹; Morton et al., 20142; Costa et al., $2019^{3}$ ), the endothelial and epithelial cells have been grown on the basal and apical surfaces of the membrane, respectively. This better mimics the uninterrupted interaction between the endothelial cells and tissue fluids (i.e. blood). It is not clear why the authors have taken the approach they have, but I think this is an important point that should be highlighted with reference to other published studies and discussed. Was there a specific reason this approach was chosen? In relation to this, in the 5-day and 14-day cultures shown in Figure 1, cells are shown on the basal surface of the membrane; this is confusing. If these represent BPAECs that have migrated to the underside of the membrane, this needs to be explained because, in effect, a double endothelial layer has been created which is not representative of the in vivo situation. Is this related to the use of $8 \mathrm{~mm}$ pores (which seems very large) and could this have been avoided by the use of a smaller pore size (which were used in other experiments - see also comment below)?

The reasoning behind the development of immortalized cell lines is logical although there are also disadvantages to this approach as demonstrated and discussed in the paper (the B2AE cell line, in particular, was not very successful). The imaging shown in Figure 3 highlights significant 
differences between the wild-type and immortalized cell lines grown on "coverglass".

Unfortunately, wild-type primary alveolar epithelial cells do not appear to have been used in subsequent bilayer experiments which would have allowed important direct comparisons to have been made between these and the immortalized cell lines. In particular, the histological section of the BATII/BPAEC layer shown in Figure 6C shows a thickened structure (and is certainly not pseudostratified) that is not representative of the native alveolar epithelium. The latter is obviously a very thin monolayer to allow for gaseous diffusion and, on this point, it would be helpful to have a figure of a histological section of ex vivo lung tissue showing the alveolar epithelium. Indeed, a more realistic single-cell layer is seen in the alveolar model created by Costa et al. (2019) ${ }^{3}$. It would be helpful to readers and potential users of the cell lines for these points to be discussed. In relation to these observations, the authors have switched between using membranes of different pore-diameters $(0.4,3.0$ and $8 \mathrm{~mm})$. Pore diameter is extremely important and selection is based on the experimental objectives. It is not clear why different pore size have been used and this could also be discussed.

\section{References}

1. Hope WW, Kruhlak MJ, Lyman CA, Petraitiene R, et al.: Pathogenesis of Aspergillus fumigatus and the kinetics of galactomannan in an in vitro model of early invasive pulmonary aspergillosis: implications for antifungal therapy.J Infect Dis. 2007; 195 (3): 455-66 PubMed Abstract | Publisher Full Text

2. Morton CO, Fliesser M, Dittrich M, Mueller T, et al.: Gene expression profiles of human dendritic cells interacting with Aspergillus fumigatus in a bilayer model of the alveolar epithelium/endothelium interface.PLoS One. 2014; 9 (5): e98279 PubMed Abstract | Publisher Full Text

3. Costa A, de Souza Carvalho-Wodarz C, Seabra V, Sarmento B, et al.: Triple co-culture of human alveolar epithelium, endothelium and macrophages for studying the interaction of nanocarriers with the air-blood barrier.Acta Biomater. 2019; 91: 235-247 PubMed Abstract | Publisher Full Text

Are a suitable application and appropriate end-users identified?

Yes

If applicable, is the statistical analysis and its interpretation appropriate?

Yes

Are the 3Rs implications of the work described accurately?

Yes

Is the rationale for developing the new method (or application) clearly explained?

Yes

Is the description of the method technically sound?

Yes

Are sufficient details provided to allow replication of the method development and its use by others?

Yes 
If any results are presented, are all the source data underlying the results available to ensure full reproducibility?

Partly

Are the conclusions about the method and its performance adequately supported by the findings presented in the article?

Yes

Competing Interests: No competing interests were disclosed.

I confirm that I have read this submission and believe that I have an appropriate level of expertise to confirm that it is of an acceptable scientific standard, however I have significant reservations, as outlined above.

Author Response 18 Jul 2019

\section{Diane Lee}

Initial experiments did involve seeding cells on opposing sides of the membrane. Owing to difficulties generating quality sections of paraffin embedded membranes, we experimented with seeding both cell types on the apical side, as described by Birkness et al.(1999) and following personal communication with the corresponding author of that paper. Following this method allowed us to compare data, since our intention was to study the interaction of bovine TB with the alveolus, making our model the bovine equivalent of that of Birkness et $a l$. On the point of mimicking the uninterrupted interaction between epithelial cells and endothelial cells, the authors suggest that in no in vivo situation will you find a synthetic membrane and that less interruption occurs when the cells are adjacent, rather than reaching through a pore. The large pores were necessary due to the intended use of the model, which would require mycobacteria and immune cells to migrate from one chamber to another. These points have now been discussed in the manuscript.

The authors whole-heartedly agree that there are disadvantages as well as advantages to the use of immortalised cell lines. These have been included at length in the modified discussion.

In light of the reviewer's suggestions, we have included extended data with regards to the wild-type ATII as part of co-culture with endothelial cells (Dataset 6 shows IF images of zstack slices, whilst dataset 7 includes raw data of the TEER values generated by culture and co-culture of each cell line and the wild-type ATII). The work of Costa et al. was published after the submission of version 1 of this manuscript, but has now been included in the discussion accordingly, as we agree that this is important to consider. We have also modified the manuscript discussion text to include justification for the different pore sizes. In brief, 0.4 was used to generate quality sections - a particular technical challenge, whilst 3 and 8 were used due to intended studies which included migration of PBMCs and mycobacteria (we notice that Costa et al. also use $3.0 \mu \mathrm{m}$, presumably for the same reason).

Competing Interests: No competing interests were disclosed. 
Reviewer Report 07 May 2019

https://doi.org/10.5256/f1000research.20472.r46560

(C) 2019 Lehr C et al. This is an open access peer review report distributed under the terms of the Creative Commons Attribution License, which permits unrestricted use, distribution, and reproduction in any medium, provided the original work is properly cited.

\section{Claus-Michael Lehr}

${ }^{1}$ Helmholtz Institute for Pharmaceutical Research Saarland (HIPS), Saarland University, Saarbrücken, Germany

2 Biopharmaceutics and Pharmaceutical Technology, Department of Pharmacy, Saarland University, Saarbrücken, Germany

\section{Patrick Carius}

${ }^{1}$ Helmholtz Institute for Pharmaceutical Research Saarland (HIPS), Helmholtz Centre for Infection Research (HZI), Saarland University, Saarland, Germany

2 Biopharmaceutics and Pharmaceutical Technology, Department of Pharmacy, Saarland University, Saarbrücken, Germany

The authors provide a detailed guide to reproduce an in vitro tissue model of the bovine air-blood barrier, that consists out of bovine pulmonary arterial endothelial cells in co-culture with one out of two different immortalized bovine alveolar epithelial cell lines.

The introduction puts the experiments in a concise but at the same well explained scientific context. The methods section is easy to follow and should allow for the reproduction of the presented model, although it could profit from some revisions:

The diameter $(\mathrm{mm})$ of all used Transwell growth supports should be exchanged by the growth area $\left(\mathrm{cm}^{2}\right)$ to easily identify the growth area.

Measurement of cell layer integrity: It is unclear if pre-warmed medium was used to restore submerged conditions and then TEER was measured after 15 min of equilibration. In our case submerged conditions are restored by adding $200 \mu \mathrm{l}$ apical and $600 \mu \mathrm{l}$ basolateral (in case of $0.33 \mathrm{~cm}^{2}$ inserts) of pre-warmed $\left(37^{\circ} \mathrm{C}\right)$ medium to the ALI cultures. TEER values are then measured after at least $1 \mathrm{~h}$ of equilibration. The TEER measurement is performed on a heating plate $\left(37^{\circ} \mathrm{C}\right)$, to prevent a fast temperature drop.

Although a detailed overview of possible applications for this model to aid the 3R's in future research is given be authors, the conclusions drawn from the displayed often appear not to be justified based on the data presented. This especially accounts for the results as well as the discussion section. The scientific benefits claimed in the "Research Highlights" appear to be exaggerated and are not based on the actually provided data.

Results section:

- In accordance with the comments of Pietro Mastroeni, a scientific discussion of the selected markers is missing. Inspiration for discussion could be taken from references $1^{1}$ and $2^{2}$. Figure $6 \mathrm{~A}$ and $\mathrm{B}$ clearly show different magnifications

Figure $6 \mathrm{C}$ and $\mathrm{D}$ show the formation of multilayered epithelia and are not further discussed.

BPAEC in Figure $7 \mathrm{~A}$ looks as the same as in Figure 7 B. Is it the same? Maybe combine into 
one figure.

Discussion section:

The model is termed a "bilayer" of epithelial and endothelial cells. As shown in Figure $6 \mathrm{C}$ and D, the BAT II culture shows the formation of multiple stacked layers, the B2AE culture at least more than two layers. This issue is not properly mentioned in the discussion.

The development of TEER values greater than $1000 \mathrm{Ohm}^{*} \mathrm{~cm}^{2}$ for the BATII cells, could be explained by the increased resistance of paracellular flux based on the formation of functional tight junctions within a monolayer (as expected in vivo) or by an increase in resistance through the formation of multilayers. The formation of functional tight junctional complexes was in this study only indicated via TEER measurement and reduction of dextran permeability; immunohistochemistry or transcriptomic data are missing. Given the context of the massive multilayer formation shown in Fig. $6 \mathrm{C}$ for the BATII culture, the missing information on tight junctional integrity would at least need a thorough discussion. The authors appear to be completely unaware of some quite relevant scientific work by other groups in the context of primary rat or human alveolar epithelial cells, resp. (See references $3^{3}$ and $4^{4}$ ) In the context of human alveolar epithelial cell lines the work of Tetley et al. ${ }^{5}$ Kuehn et al. ${ }^{6}$ should be considered. The same is true for the work as regards cocultures of alveolar epithelial cells and immune cells by Rothen-Rutishauser et al. ${ }^{7}$ Hittinger et al. ${ }^{8}$ Kletting et. al. ${ }^{9}$. A very recent paper by Costa et al. ${ }^{10}$ describes a co-culture of human alveolar epithelial cells, endothelial cells and macrophages.

The whole discussion could benefit of an even more critical reflection of the advantages as well as disadvantages of the proposed model.

Are a suitable application and appropriate end-users identified?

Yes

If applicable, is the statistical analysis and its interpretation appropriate?

Yes

Are the 3Rs implications of the work described accurately?

Yes

\section{References}

1. Marconett CN, Zhou B, Sunohara M, Pouldar TM, et al.: Cross-Species Transcriptome Profiling Identifies New Alveolar Epithelial Type I Cell-Specific Genes.Am J Respir Cell Mol Biol. 56 (3): 310-321 PubMed Abstract | Publisher Full Text

2. Imai-Matsushima A, Martin-Sancho L, Karlas A, Imai S, et al.: Long-Term Culture of Distal Airway Epithelial Cells Allows Differentiation Towards Alveolar Epithelial Cells Suited for Influenza Virus Studies.EBioMedicine. 2018; 33: 230-241 PubMed Abstract | Publisher Full Text

3. Dobbs LG: Isolation and culture of alveolar type II cells.Am J Physiol. 1990; 258 (4 Pt 1): L134-47 PubMed Abstract | Publisher Full Text

4. Elbert K, Schäfer U, Schäfers H, Kim K, et al.Pharmaceutical Research. 1999; 16 (5): 601-608 Publisher Full Text

5. Kemp SJ, Thorley AJ, Gorelik J, Seckl MJ, et al.: Immortalization of human alveolar epithelial cells to investigate nanoparticle uptake.Am J Respir Cell Mol Biol. 2008; 39 (5): 591-7 PubMed Abstract I Publisher Full Text

6. Kuehn A, Kletting S, de Souza Carvalho-Wodarz C, Repnik U, et al.: Human alveolar epithelial cells expressing tight junctions to model the air-blood barrier.ALTEX. 2016; 33 (3): 251-60 PubMed Abstract | Publisher Full Text 
7. Rothen-Rutishauser BM, Kiama SG, Gehr P: A three-dimensional cellular model of the human respiratory tract to study the interaction with particles.Am J Respir Cell Mol Biol. 2005; 32 (4): $281-9$ PubMed Abstract | Publisher Full Text

8. Hittinger $\mathrm{M}$, Janke J, Huwer $\mathrm{H}$, Scherließ R, et al.: Autologous co-culture of primary human alveolar macrophages and epithelial cells for investigating aerosol medicines. Part I: model characterisation.Altern Lab Anim. 2016; 44 (4): 337-347 PubMed Abstract

9. Kletting S, Barthold S, Repnik U, Griffiths G, et al.: Co-culture of human alveolar epithelial (hAELVi) and macrophage (THP-1) cell lines.ALTEX. 2018; 35 (2): 211-222 PubMed Abstract |

Publisher Full Text

10. Costa A, de Souza Carvalho-Wodarz C, Seabra V, Sarmento B, et al.: Triple co-culture of human alveolar epithelium, endothelium and macrophages for studying the interaction of nanocarriers with the air-blood barrier.Acta Biomater. 2019. PubMed Abstract | Publisher Full Text

Are a suitable application and appropriate end-users identified?

Yes

If applicable, is the statistical analysis and its interpretation appropriate?

Yes

Are the 3Rs implications of the work described accurately?

Yes

Is the rationale for developing the new method (or application) clearly explained? Yes

Is the description of the method technically sound?

Yes

Are sufficient details provided to allow replication of the method development and its use by others?

Partly

If any results are presented, are all the source data underlying the results available to ensure full reproducibility?

Yes

Are the conclusions about the method and its performance adequately supported by the findings presented in the article?

Partly

Competing Interests: No competing interests were disclosed.

Reviewer Expertise: Advanced Drug Delivery Technologies; cell and tissue models of epithelial barriers (intestines, skin, lung)

We confirm that we have read this submission and believe that we have an appropriate level 


\section{of expertise to confirm that it is of an acceptable scientific standard, however we have significant reservations, as outlined above.}

Author Response 18 Jul 2019

\section{Diane Lee}

The authors have modified the manuscript to include the surface area of the Transwell inserts, in addition to the diameter throughout the manuscript. In performing TEER measurements, medium was pre-warmed (in the incubator). We do not have a heating plate and therefore some loss of temperature was inevitable. To help counteract this, we take three measurements from all wells (for each measurement working from the first to last sample before starting again at the first), to monitor the extent of TEER change with temperature. This has been clarified in the methods. We did calculate drift for eight inserts between the first and last measurements. In these calculations, TEER increased between 3 and $25 \%$ (Mean $9 \pm 8 \%$ ) for the BATII co-cultures and 3 and $22 \%$ (Mean of $7 \pm 6 \%$ ) for B2AE co-cultures respectively. Drift was highest in the earlier measurements (day 3 ) in both cases. Until co-culture studies using the proposed model are performed at length and data from multiple groups compared, it's not possible to say for sure how much of a benefit any model will provide to the field. The authors continue to refine the model and encourage others to collaborate or make use of this approach in their own studies. With regards to scientific benefits, there are studies which simply cannot be performed in live bovines at present; these particularly include the early (and transient) events which occur during infection with pathogens such as M.bovis, or RSV. We hope that the benefits of such an approach as the one proposed in the current paper are clarified by our extended discussion.

We have further clarified why we chose the markers used in this study and included further discussion as appropriate. We thank the observant reviewer for highlighting the discrepancy in Figure 6 and have corrected the figure accordingly. With regards to the comments on Figure $6 \mathrm{C}$ and $\mathrm{D}$, we have added to both the results section and discussion section with regards to the multi-layered epithelial layers in the bilayers generated by BATII. These were isolated in the ALI cultures, their presence being easily identified using $x-z$ confocal microscopy, as shown in Figure 5 and the extended data. We have discussed these morphological anomalies further in the text. The data for BPAEC in Figure 7A and 7B are from different experiments/sets of data. The actual values are $55.7 \pm 5.2$ and $48 \pm 3.4 \%$ respectively.

The authors concede that in areas, the model is more than two cells thick, although this is not universal across the membrane (shown by the $x-z$ confocal images of Figure 5 and extended data). We have included a further image (E) in Figure 6 to put these 3D structures in context and expanded the discussion accordingly, including whether it would be more accurate to describe the model as 'co-culture'. It should be noted, however, that in our studies, the wild type ATII cells also formed 3D structures when grown on membranes in coculture with BPAEC (see Dataset 6, which shows frames from an ATII/BPAEC co-culture Zstack). This occurred whether in co-culture with the endothelial BPAEC, as in the current study, or when seeded as a mono-culture, as in our previous paper (see Lee et al. 2018). We accept that the use of the term 'bilayer' in this instance is not accurate and have modified the manuscript to describe the model as a co-culture, rather than a bilayer.

TEER values of $>1000$ were also generated for wild-type ATII co-cultures with endothelial cells, which we have included in the extended data (Dataset 5 and 7). As clarified above (and 
further clarified in the text), the 3D structures were not uniform in thickness. The thickness ranged from one cell upwards. It is our experience that TEER values represent the area of the lowest integrity in the culture i.e. the thinnest/with the fewest number of functional tight junctions. This is evidenced by the drop in TEER in cultures damaged by experimental manipulations (scrape by pipette and so on). Dataset 5 contains raw includes raw TEER data for BATII/B2AE only, BPAEC only, WT only and each as part of a co-culture of epithelial/endothelial cells, plotted as dataset 7. We have not included IHC data as the antibodies we tried (ZO-1 and Occludens) were cross-reactive with other antigens or generated high background signal. This lowered our confidence in their suitability for their use in the characterisation of the model.

The authors are indeed aware of the work of Kemp et al. (referred to as Tetley above). Whilst they do consider the work relevant to discussions of immortalised cell lines, Kemp et al. transduced a temperature sensitive mutant of SV40 and cultured the resulting cells without other cell types. We have extended the discussion to further consider this and the work of other groups. We have recently completed studies of the interaction of the co-culture model of the current study with immune cells (PBMCs). As the current paper is a methods paper, we focussed here on the setup of the model and a manuscript detailing our latter work is in preparation.

Competing Interests: No competing interests were disclosed.

Reviewer Report 05 April 2019

https://doi.org/10.5256/f1000research.20472.r46557

(c) 2019 Mastroeni P. This is an open access peer review report distributed under the terms of the Creative Commons Attribution License, which permits unrestricted use, distribution, and reproduction in any medium, provided the original work is properly cited.

\section{Pietro Mastroeni}

Department of Veterinary Medicine, University of Cambridge, Cambridge, UK

The paper describes the generation and characterisation of two immortalised bovine epithelial cell lines to be used in conjunction with bovine arterial endothelial cells for the creation of structures that would model the alveolar environment of bovine species. The authors very clearly list the potential applications of such approach and its impact on the 3Rs. It would be desirable to explain in more depth what is the incontrovertible evidence that such models are truly representative of an in vivo situation.

The introduction is very clear and comprehensive and allows the reader to gain information on the background to the study and on the general context of the experiments.

The methods section is also clear and detailed, thus allowing reproducibility of the experiments.

There are a few points that the authors might want to address in their revision of the manuscript.

1. Figure 3. The pictures relative to the wild type cells are hugely different from the ones 
obtained when using either of the cell lines. This might be confusing for the reader who may wonder how such large morphological differences can then lead to the conclusion that the immortalised cells lines are a good model for the natural alveolar environment. Perhaps this needs to be explained more clearly and discussed in detail.

2. In some sections the authors describe results for only one cell line (e.g. Matrigel cultures) whilst in others they cover both cell lines. This may be confusing.

3. A clear explanation of the choice of the cell markers is not always provided in the results section. This would make the manuscript clearer.

4. It might be helpful to have a conclusive statement at the end of each section of the results to state the main findings and conclusions of that particular set of experiments. Similarly, a sentence introducing each section and explaining why the experiments were done would add clarity. This is done for some results sections but not for others. Therefore, sometimes the reader is left to wonder.....why are they doing this?

5. It might be useful to show some histological and immune-fluorescence pictures of alveolar structures from a bovine lung to show the extent of similarities and differences between the proposed approach and the mammalian alveolar structure.

6. Alveolar macrophages (together with other immune cells) are a key to lung homeostasis and protection against infectious diseases. It needs explaining how structures devoid of such important immune cells can be considered representative of an in vivo situation, especially when one of the intended uses would be the study of infectious diseases.

7. The approach described in this study entails the generation of cell lines from a single animal. How can the authors be sure that these cell lines would be representative especially when dealing with a species that is clearly outbred. What are the dangers of animal-toanimal variability and therefore lack of representativeness?

Are a suitable application and appropriate end-users identified?

Yes

If applicable, is the statistical analysis and its interpretation appropriate? Yes

Are the 3Rs implications of the work described accurately? Yes

Are a suitable application and appropriate end-users identified? Partly

If applicable, is the statistical analysis and its interpretation appropriate? Partly

Are the 3Rs implications of the work described accurately?

Partly

Is the rationale for developing the new method (or application) clearly explained? Yes

Is the description of the method technically sound? 
Are sufficient details provided to allow replication of the method development and its use by others?

Yes

If any results are presented, are all the source data underlying the results available to ensure full reproducibility?

Yes

Are the conclusions about the method and its performance adequately supported by the findings presented in the article?

Yes

Competing Interests: No competing interests were disclosed.

Reviewer Expertise: Infection, Immunity, Histopathology, tissue microbiology, molecular biology, vaccines, antibiotics. Referee suggested by the NC3Rs for their scientific expertise and experience in assessing $3 R s$ impact

\section{I confirm that I have read this submission and believe that I have an appropriate level of expertise to confirm that it is of an acceptable scientific standard, however I have significant reservations, as outlined above.}

Author Response 18 Jul 2019

\section{Diane Lee}

The authors acknowledge that here, as in many cell lines, there are morphological differences when compared to the wild type when grown on coverglass. We attributed this to the increased proliferation rate of the BATII cell line and the lack of contact inhibition, characteristic of SV40 Large T Antigen transformed cells. The B2AE cell line was slower by comparison and did not form multi-layered structures on coverglass. Although we still observed multilayer structures in co-cultures generated using the BATII cell line (and to a lesser extent, the wild-type ATII), these covered $<20 \%$ of the culture surface, being surrounded by thinner mono/bilayers of epithelial-like cells. We have expanded the results section to clarify and also included a discussion of the advantages versus disadvantages of using cell lines which differ in phenotype from their wild-type counterparts.

The omission of the B2AE cell line from some experiments was due to the growth rate of $B 2 A E$ being very slow and not generating enough stocks to perform experiments with meaningful numbers of replicates. We chose to therefore focus on the BATII cell line for some experiments and have clarified as such in the text.

We have added explanations or further clarification to justify choice of marker in each instance, along with references where necessary. Conclusive statements have also now been included or extended for the results sections, along with the inclusions of an introductory sentence or two.

We have included an H\&E image and highlighted differences/similarities between the proposed model and alveolar architecture in discussion. In addition, the inclusion of immune cells has been added to the discussion - studies including peripheral blood 
mononuclear cells (PBMCs) have been performed and are being published separately as part of further studies of M.bovis-BCG interaction with the bovine alveolus (manuscript in preparation).

Lastly, the authors concede that this is from a single animal and therefore cannot be entirely representative of a whole species or even breed. We have added further to the discussion to this effect, with additional emphasis on the positives and negatives of the utilisation of cell lines when modelling the in vivo situation. We have also published detailed protocols of the isolation procedure, enabling researchers to isolate cells from multiple animals and compare phenotypes.

Competing Interests: No competing interests were disclosed.

The benefits of publishing with F1000Research:

- Your article is published within days, with no editorial bias

- You can publish traditional articles, null/negative results, case reports, data notes and more

- The peer review process is transparent and collaborative

- Your article is indexed in PubMed after passing peer review

- Dedicated customer support at every stage

For pre-submission enquiries, contact research@f1000.com 